\title{
MASTER
}

DOE/NASA CONTRACTOR

DOE/NASA CR-150874 REPORT

\section{ANALYSIS AND EXPERIMENTAL TESTS OF A HIGH-PERFORMANCE EVACUATED TUBULAR COLLECTOR}

Prepared from documents furnished by

Owens-Illinois

P. O. Box 1035

Toledo, Ohio 43666

Under Contract NAS8-32259 with

National Aeronautics and Space Administration

George C. Marshall Space Flight Center, Alabama 35812

For the U. S. Department of Energy

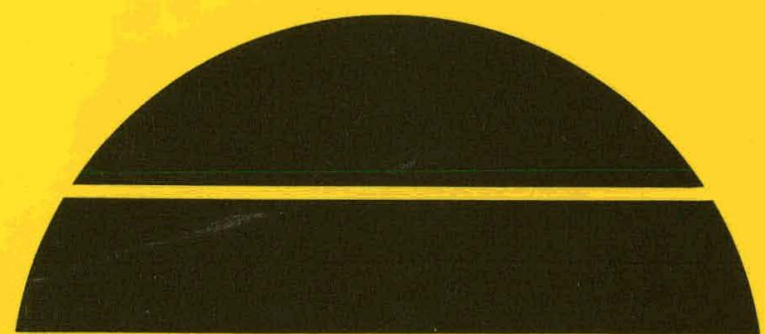

\section{U.S. Department of Energy}




\section{DISCLAIMER}

This report was prepared as an account of work sponsored by an agency of the United States Government. Neither the United States Government nor any agency Thereof, nor any of their employees, makes any warranty, express or implied, or assumes any legal liability or responsibility for the accuracy, completeness, or usefulness of any information, apparatus, product, or process disclosed, or represents that its use would not infringe privately owned rights. Reference herein to any specific commercial product, process, or service by trade name, trademark, manufacturer, or otherwise does not necessarily constitute or imply its endorsement, recommendation, or favoring by the United States Government or any agency thereof. The views and opinions of authors expressed herein do not necessarily state or reflect those of the United States Government or any agency thereof. 


\section{DISCLAIMER}

Portions of this document may be illegible in electronic image products. Images are produced from the best available original document. 
NOTICE

This report was prepared to document work sponsored by the United States Govermment. Nelther the United States nor its agents the United States Departmant of Energy, the United States National Agronaut1cs and Space Adminfetration, nor any federsl employees, nor any of thef: contractors, sulccrisractors or the1r employees, make any warranty, express or 1riflite, or assume any legal liablitty or responsibdlity for the sccisacy, completeness, or usefulness of any information, apparatus, product or process disclosed, or represent that its use would not Infringe privately owned rights. 


\begin{tabular}{|c|c|}
\hline $\begin{array}{l}\text { 1. REPORT NO. } \\
\text { DOE/ NASA CR-150874 }\end{array}$ & 3. RECIPIENT'S CATALOG NO. \\
\hline \multirow{2}{*}{$\begin{array}{l}\text { 4. TITLE AND SUBTITLE } \\
\text { Analysis and Experimental Tests of a High-Performance } \\
\text { Evacuated Tubular Collector }\end{array}$} & $\begin{array}{l}\text { 5. REPORT DATE } \\
\text { December } 1978\end{array}$ \\
\hline & 6: PERFORMING ORGANIZATION CGIDE \\
\hline $\begin{array}{l}\text { 7. AUTHOR(S) } \\
\text { D. C. Beekley and G. R. Mather, Jr. }\end{array}$ & 8. PERFORMING ORGANIZAT!ON REPORT \# \\
\hline \multirow{3}{*}{$\begin{array}{l}\text { 9. PERFORMING ORGANIZATION NAME AMD ADDRESS } \\
\text { Owens-Ilinois } \\
\text { P. O. Box } 1035 \\
\text { Toledo, Ohio } 43666\end{array}$} & 10. WORK UNIT, NO. \\
\hline & $\begin{array}{l}\text { 11. CONTRACT OR GRANT NO. } \\
\text { NAS8-32259 }\end{array}$ \\
\hline & 13: TYPE OF REPOR' \& PERIOD COVEREO \\
\hline \multirow{3}{*}{$\begin{array}{l}\text { 12. SPONSORING AGENCY NAME AND ADDRESS } \\
\text { National Aeronautics and Space Administration } \\
\text { Washington, D. C. } 20546\end{array}$} & Contractor Report \\
\hline & . \\
\hline & 14. SPONSORING AGENCY COODE \\
\hline
\end{tabular}

15. SUPPLEMENTARY NOTES

This work was done under the technical management of $\mathrm{Mr}$. John Caudle, George C. Marshall Space Flight Center.

16. ABSTRACT

A high-performance collector based on the use of all-glass, evacuated tubular collector elements is described and analyzed, and supporting experimental data presented. The collector operates with excellent efficiency at temperatures high enough to drive existing air conditioning units, and shows good performance under diffuse light and low insolation conditions. Collector efficiency is insensitive to operating temperature, ambient temperature, and wind speed. In addition, air as well as liquid can be used as the heat transfer fluid, with no significant performance penalty. While the equations. governing the useful energy produced can be cast in a form similar to that for flat plate collectors, several important parameters are unique in a number of respects. The loss coefficient $U_{\text {}}$ is unusually low, while the flow factor $F_{B}$ and effective insolatioh $S_{\text {ff }}$ are unusually high. It is shown


can be enhanced significantly by the use of a reflecting screen behind the tubes. The instantaneous efficiency of the collector is found to be greater at the beginning and end of a day than at solar noon, and for this reason it is argued that collector performance should be judged on the basis of daily rather than instantaneous efficiency or energy output.

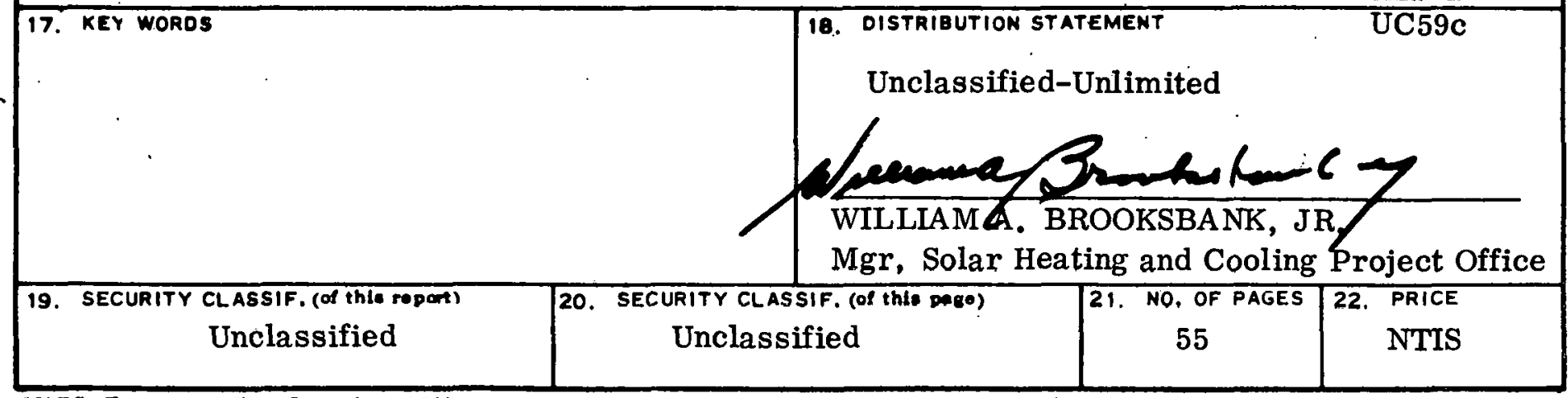


THIS PAGE

\section{WAS INTENTIONALLY LEFT BLANK}


TABLE OF CONTENTS

I. Introduction

II. Collector Performance Model

III. Effect of Design Parameters on Collector Performance

IV. Experimental Tests of Collector Arrays

V. Transient Behavior

VI. Discussion

VII. Acknowledgments






\section{INTRODUCTIOH}

The solar collector discussed in this paper is an all-giass, selectively coated, evacuated collector. The collector consists of three glass tubes inside one another as shown schematically in Fig. l. The middle tube is the absorber tube which is covered on the outside. with a coating that has the properties of high absorptance in the solar spectrum and low emittance in the infrared spectrum. The largest tube or cover tube surrounds the absorber tube and is sealed to it at one end. The annular space between these two tubes is evacuated so that heat transfer by conduction and convection is essentially eliminated between the two tubes. At the same time the cover tube provides protection from the environment for the selectively coated surface. A third, smaller tube is inserted tnside the absorber tube for delivery of the working fluid; thus the inlet and the outlet for the working flutd are at the same end of the tube. This design makes manifolding of the collector tubes into an array convenient. Table 1 gives the dimensions of the three tubes in a single assembly, while Fig. 2 is a photograph of a collector array at the Owens-Iilinois, Inc. test site in. Toledo, Ohio.

\section{COLLECTOR PERFORMANCE MODEL}

The useful heat obtained from a single collector tube can be expressed in a form similar to that for flat plate collectors [1]:

$$
Q_{U}=F_{R} A_{C}\left[\alpha \tau S_{\text {eff }}-U_{L}\left(A_{L} / A_{C}\right)\left(T_{\text {in }}-T_{a}\right)\right]
$$

where $A_{C}$ is the absorber tube diameter times the collector length and $A_{L}$ is equal to $\pi A_{C}$.

Three terms in this equation are discussed in some detail in the following paragraphs: $F_{R}$, the performance index; $S_{e f f}$, the effective insolation on the collector; and $U_{L}$, the collector loss coefficient. 
A. Collecter Ferformance Equation Equaticas (2) and (3) are derived from the heat balance of control volumes involving the delivery tube, annulus and associated tube surfaces. Figure 3 indicates the location of these control volumes. Since water is assumed as the working fluid, the heat capacity of the several glass tubes can be neglected as small compared with the heat capacity of the water.

$$
\begin{aligned}
& \rho_{f} C_{p} A_{x 1}\left(\partial T_{1} / \partial t\right)+\dot{m} C_{p}\left(\partial T_{1} / \partial x\right)+U_{1} P_{1} T_{1}-U_{1} P_{1} T_{2}=0 \\
& \rho_{f} C_{p} A_{x 2}\left(\partial T_{2} / \partial t\right)-\dot{m}_{p}\left(\partial T_{2} / \partial x\right)-U_{1} P_{1} T_{1}+\left\{U_{1} P_{1}+\right. \\
& \left.U_{L} P_{L} /\left[1+\left(U_{L} P_{L} / U_{3} P_{3}\right)\right]\right\} T_{2}=\left\{1 /\left[1+\left(U_{L} P_{L} / U_{3} P_{3}\right)\right]\right\}\left(a r S_{e f f} P_{C}+U_{L} P_{L} T_{a}\right)
\end{aligned}
$$

The equations (2) and (3) were solved in terms of the following reduced variables:

$$
\xi=\left(U_{3} P_{3} / \dot{m} C_{p}\right) x ; \hat{t}=\left(U_{3} P_{3} / p_{f} C_{p} A_{x 2}\right) t
$$

and the following parameters:

$$
\begin{aligned}
& a=A_{x 1} / A_{x 2} ; b=U_{1} P_{1} / U_{3} P_{3} ; b^{\prime}=b+1-F^{\prime} \\
& F^{\prime}=1 /\left[1+\left(U_{L} P_{L} / U_{3} P_{3}\right)\right] ; T_{e}=\left(\alpha \tau S_{e f f} P_{c} / U_{L} P_{L}\right)+T_{a}
\end{aligned}
$$

The steady state condition occurs when $\partial T_{1} / \partial \hat{t}=\partial T_{2} / \partial \hat{t}=0$ and $T_{e}$ is constant. These conditions never exist in practice, but in many situations the collector can be described as operating in a "quasi" steady condition where the steady state solution gives a good approximation to the collector behavior.

With the steady state assumptions, and the boundary conditions: $T_{1}(0)=T_{\text {in }}$ and $T_{1}\left(\xi_{1}\right)=T_{2}\left(\xi_{1}\right),\left(\xi_{1}=U_{3} P_{3} l / \dot{m} C_{p}\right)$, the filuid temperatures along the length of the collector tube are given by equations (4) and (5).

$$
\begin{aligned}
& T_{1}(\xi)=T_{e}+\left(T_{\text {in }}-T_{e}\right) e^{\omega_{1} \xi_{1}} \cdot\left\{\left[\cosh \omega_{2}\left(\xi_{1}-\xi\right)+\left(\omega_{1} / \omega_{2}\right) \sinh \omega_{2}\left(\xi_{1}-\xi\right)\right] /\right. \\
& \left.\left[\cosh \omega_{2} \xi_{1}+\left(\omega_{1} / \omega_{2}\right) \sinh \omega_{2} \xi_{1}\right]\right\}
\end{aligned}
$$




$$
\begin{aligned}
& T_{2}(\xi)=T_{e}+\left(T_{i n}{ }^{-T} \cdot e\right) e^{\omega_{1} \xi_{1}}\left\{\left[\cosh \omega_{2}\left(\xi_{1}-\xi\right)-\left(\omega_{1} / \omega_{2}\right) \sinh \omega_{2}\left(\xi_{1}-\xi\right)\right] /\right. \\
& \left.\left[\cosh \omega_{2} \xi_{1}+\left(\omega_{1} / \omega_{2}\right) \sinh \omega_{2} \xi_{1}\right]\right\}
\end{aligned}
$$

where

$$
\begin{aligned}
& w_{1}=U_{L} P_{L} F^{\prime} / 2 U_{3} P_{3} \\
& w_{2}=U_{L} P_{L} F^{\prime}\left[1+4 U_{1} P_{1} / U_{L} P_{L} F^{\prime}\right]^{1 / 2} / 2 U_{3} P_{3}
\end{aligned}
$$

The useful heat obtained from the collector tube is:

$$
\begin{aligned}
& Q_{u}=\dot{m} C_{p}\left[T_{2}(0)-T_{1}(0)\right]=\left\{\sinh \omega_{2} \xi_{1} /\left[\omega _ { 2 } \xi _ { 1 } \left(\cosh \omega_{2} \xi_{1}+\right.\right.\right. \\
& \left.\left.\left.\left(\omega_{1} / \omega_{2}\right) \sinh \omega_{2} \xi_{1}\right)\right]\right\} F^{\prime} A_{c}\left[\alpha \tau S_{e f f}-U_{L}\left(A_{L} / A_{C}\right)\left(T_{i n}-T_{a}\right)\right]
\end{aligned}
$$

Equation (7) provides the definition of $F_{R^{\prime}} / F^{\prime}$, the performance index.

$$
F_{R^{\prime}} / F^{\prime} \equiv \sinh \omega_{2} \xi_{1} /\left\{\omega_{2} \xi_{1}\left[\cosh \omega_{2} \xi_{1}+\left(\omega_{1} / \omega_{2}\right) \sinh \omega_{2} \xi_{1}\right]\right\}
$$

B. Loss Coefficient The effectiveness of a solar collector is determined primarily by the amount of heat lust from the collector during operation. This heat loss governs the potential operating temperature of the collector and the level of insolation required in order for operation to be feasible. Fundamentally, the heat loss is the product of a loss coefficient, loss area and temperature difference. While the heat loss can be reduced by reducing any one of these terms, the loss coefficient is the term that is most readily made smaller by application of engineering and scientific techniques. Various schemes have been proposed and used to reduce the loss coefficient $U_{L}$. In this collector, a vacuum and spectrally selective coating have been used to good effect.

The heat loss in the collector is controlled by radiation loss from the selectively coated absorber surface to the cover tube inner surface. Using the subscript scheme in Figure 3 to identify the surfaces, a combined radiation, conduction and convection heat loss network is drawn 
in Figure 4.

The heat lost by the collector is given by Eq. (8),

$$
Q_{L}=U_{L} A_{4}\left(T_{4}-T_{a}\right)
$$

where

$$
U_{L}=\left[1 / h_{1}+1 / h_{2}+1 / h_{3}\right]^{-1}
$$

and

$$
\begin{aligned}
& \left.h_{1}=\sigma\left(T_{4}+T_{5}\right)\left(T_{4}{ }^{2}+T_{5}{ }^{2}\right) /\left\{\left[\left(1-\varepsilon_{4}\right) / \varepsilon_{4}\right]+\left(1 / F_{45}\right)+\left[\left(1-\varepsilon_{5}\right) / \varepsilon_{5}\right]\left(A_{4} / A_{5}\right)\right]\right\} \\
& h_{2}=k /\left[\left(D_{4} / 2\right) \ln \left(D_{6} / D_{5}\right)\right] \\
& h_{3}=\left[h+\varepsilon_{6} \sigma\left(T_{6}+T_{a}\right)\left(T_{6}{ }^{2}+T_{a}{ }^{2}\right)\right]\left(A_{6} / A_{4}\right)
\end{aligned}
$$

The loss coefficient $U_{L}$ is that for an area $A_{4}$, which is the collector loss area $A_{L}$.

C. Insolation on Tubes in an Array The collector tubes are axially symmetric and have an aperture of $360^{\circ}$ for light collection, facts that can be used to advantage in building up multi-tube collector arrays. As will be shown in this section, the insolation available to a tube can be increased substantially if the tubes in an array are suitably spaced apart and a reflecting screen is placed behind them. As a result, it is possible to achieve a highly cost effective collector array whose thermal performance on an installed area basis is excellent.

Spacing of the tubes enhances the available insolation in a number of ways. First, each tube has an intercept area which can be made irdependent of sun angle between limits set by tube spacing, which determines when shading from neighboring tubes occurs. Second, the diffuse light available to a given tube is generally greater than that available to a planar surface occupying the same project area, and this component increases with tube spacing. Finally, light passing through the gaps between the tubes is reflected onto the undersides by the backing screen, and the amount intercepted 
by a tube increases with tube spacing.

The detalls of these effects are discussed in the folloring paragraphs for the case in which the tube axes are in a north-south orientation. While either diffusely or specularly reflecting surfaces in a variety of shapes can be used as a backing screen, the case to be examined is that of a planar, diffusely reflecting surface such as is used with present tubular collector arrays. A major argument for choosing such a surface is that it could consist of standard roofing materials over which the array would be installed, and thereby enhance performance significantly whlle adding little or no cost to the collector. All that would be needed is a reflective outdoors paint to increase the reflectance of the screen.

1. Beam Component A tube in an array intercepts the beam component of insolation both directly, on the cross sectional area of the absorber tube, and indirectly from reflections off the backing surface. The directly intercepted beam component can be determined by considering a tube axis in a north-south orientation tilted at an angle s above the horizontal at latitude $L$. If $S_{B O}$ is the beam radiation in a plane perpendicular to the sun's rays, which are incident at declination $\delta$, and the hour angle $\omega$ is taken to be zero at solar noon, it is straightforward to show that the component $S_{B D}^{\prime}$ intercepted directly by the absorber tube is

$$
S^{\prime}{ }_{B D}=S_{B O}\left\{1-[\sin (s-L) \cos \delta \cos \omega+\cos (s-L) \sin \delta]^{2}\right\}^{1 / 2}
$$

Equation (9) is valid only so long as the tube is not shaded by neighboring tubes. For an array with tubes spaced at distance $d$, however (see Fig. 5), shading begins to occur at hour angles $|\omega| \geq\left|\omega_{0}\right|$, where

$$
\left|\omega_{0}\right|=\cos ^{-1}\left[\left(D_{4}+D_{6}\right) / 2 d\right]
$$


Shading can be taken into account through a factor $g(\omega)$, which is given by

$$
\begin{aligned}
g(\omega) & =1,|\omega| \leq\left|\omega_{0}\right| \\
& =\frac{d}{D_{4}} \cos \omega+\frac{1}{2}\left(1-\frac{D_{6}}{D_{4}}\right),|\omega|>\left|\omega_{0}\right|
\end{aligned}
$$

The beam component intercepted directly by a tube in an array is then $S_{B D}=g(w) S_{B D}^{\prime}$. The quantity $S_{B D}$ can be written in terms of the beam radiation on a horizontal surface, $S_{B H}$, by using the relation $S_{B D}=R_{T} S_{B H}$, where [2]

$$
R_{T}=g(\omega) \frac{\left\{1-[\sin (s-L) \cos \delta \cos \omega+\cos (s-L) \sin \delta]^{2}\right\}^{1 / 2}}{\cos \delta \cos L \cos \omega \dot{\omega}+\sin \delta \sin L}
$$

In practice, it is a good approximation to assume that $D_{4} \approx D_{6}$ for the purpose of evaluating the shading factor $g(\omega)$. Then, for example, if $d=2 D_{6},\left|\omega_{0}\right|=60^{\circ}$ and the individual tubes are unshaded for eight hours a day. If the tilt angle $s$ is equal to the latitude $L$, it can be seen from Eq. (9) that $S_{B D}$ is independent of $w$ during this eight hour period. In fact, one finds in this case that

$$
\begin{aligned}
S_{B D} & =S_{B 0} \cos \delta,|\omega| \leq \cos ^{-1} D_{6} / d \\
& =\frac{S_{B 0} d}{D_{6}} \cos \delta \cos \omega,|\omega|>\cos ^{-1} D_{6} / d
\end{aligned}
$$

In addition to the directly intercepted beam component $S_{B D}$, the tubes in an array also receive a component $S_{B R}$ due to reflections of beam light from the backing surface. In general, the back-reflected light will have . specular as well as diffuse character, but for the purpose of estimating the component $S_{B R}$ we will assume completely diffuse reflections. Figure 5 specifies the geometry of the array. Beam radiation passes between the spaced tubes, giving rise to a series of light strips whose widths $W$ and 
center positions $x_{i T}$ relative to the axis of a given tube both vary with hour angle w.

$$
\begin{aligned}
& W=d-D_{6} / \cos \omega \\
& x_{i T}=D_{B} \tan \omega+(i+1 / 2) d
\end{aligned}
$$

The rate at which beam energy arrives at each strip is $Q_{B \text { in }}=R_{P} S_{B H} W l$, where $R_{p}$ is the angle factor for converting beam radiation on a horizontal surface to a south facing surface tilted at angle s:[2]:

$$
R_{P}=\frac{\cos (L-S) \cos \delta \cos \omega+\sin (L-S) \sin \delta}{\cos L \cos \delta \cos \omega+\sin L \sin \delta}
$$

If the backing screen has diffuse reflectance $\rho$, the rate at which energy is reflected is $Q_{B o u t}=\rho R_{P} S_{B H} W l$. The fraction of the energy reflected from a strip at $X_{i T}$ that is incident on the tube of interest is therefore

$$
Q_{B T}(i)=\rho R_{P} S_{B H} W^{W} F_{i T}
$$

where $F_{i T}$ is the geometric shape factor of the strip at $X_{i T}$ and the tube. The total energy $Q_{B T}$ from all strips can be obtained by summing the contributions in Eq. (17) over all strips. In addition to the light from the strips, a given tube will also receive reflected light from the overhanging screen at either end of the array. While this contribution can be important for tubes near the ends of the array, it is neglected here both for simplicity and because its importance to the overall performance of a large array is smal1. Thus, if the back-reflected beam flux is defined as $S_{B R}=Q_{B T} / D_{4} \chi$ (i.e., energy per unit of absorber tube cross section area, for consistency with the directly intercepted flux, $S_{B D}$ ), one has

$$
S_{B R}=\frac{W}{D_{4}} \rho R_{P} S_{B H} \sum_{i}^{\sum} F_{i T}
$$


The shape factors $F_{i T}$ for those strips whose views of the tube is unobstructed by other tubes can be evaluated by Hottel's crossed and uncrossed string method [3]. In fact, it is found that

$$
F_{i T}=\frac{D_{4}}{2 W} \tan ^{-1} \frac{W / D_{B}}{1+\left(x_{i T}{ }^{2}-W^{2} / 4\right) / D_{B}{ }^{2}}
$$

For those strips whose view is partially obstructed by other tubes, the shape factors are more complicated. However, such strips lie relatively far away from the tube of interest so that the contributions of their shape factors to the sum in Eq. (18) is relatively small. Thus, it is a good approximation to use Eq. (19) for all the shape factors appearing in Eq. (18). Combining Eqs. (18) and (19), $S_{B R}$ becomes

$$
S_{B R}=\frac{\rho R_{P} S_{B H}}{2} \sum_{i} \tan ^{-1} \frac{W / D_{B}}{1+\left(X_{i T^{2}}-W^{2} / 4\right) / D_{B}^{2}}
$$

Equation (20) is cumbersome to evaluate and does not lend itself to simplified approximations for arbitrary tube spacings $d$ and screen distances $D_{B}$. A detailed analysis shows that for $d \leq 2 D_{6}$ an excellent approximation to Eq. (20) is

$$
S_{B R}=\rho R_{P} S_{B H} W / D_{6}
$$

where

$$
\left.\Delta \equiv \frac{D_{6}}{D_{4}} \Sigma^{j} F_{i T}\right|_{\omega=0}
$$

For spacings $d>2 \mathrm{D}_{6}$, however, Eq. (21) is not a good approximation to Eq. (20).

The portion of the beam component striking the outer edges of the cover tubes is near grazing incidence and therefore is largely reflected. 
Some of this radiation reaches neighboring tubes both directiy and indirectly, via secondary reflections from the screen. Test results have proven the overall contribution of these reflections to be small, and so it is neglected in the present analysis.

2. Diffuse Component As in the case of the beam component, the diffuse component of insolation is intercepted both directly by the tubes and indirectly from reflections off the backing screen. If the apparent origin of the diffuse radiation is localized over a region of sky near the solar disk, as might be the case on a clear day, it is reasonable to treat the diffuse component as beam radiation and use the total insolation in place of the beam insolation in the equations developed in Section C.1. If, at the other extreme, the diffuse component is distributed uniformly over the sky dome, as might be the case on a cloudy or hazy day, its contribution to the total insolation on an array of tubes must be calculated separately. In the discussion that follows, it will be assumed that the diffuse insolation is distributed uniformly over the sky dome. Assume first that the collector tilt s is zero so that ground reflections need not be considered. Then, if $S_{d}$ is the diffuse insolation from the sky dome and $F_{T S}$ the shape factor of an absorber tube and the sky, the diffuse flux intercepted directly by the absorber tube is

$$
S_{\mathrm{dD}}=\pi \mathrm{F}_{\mathrm{TS}} \mathrm{S}_{\mathrm{d}}
$$

As before, the flux $S_{d D}$ is defined per unit of cross section absorber tube area.

The component $S_{d R}$ of diffuse radiation reflected off the backing screen must be added to $S_{d D}$. Consider a thin strip of backing screen with width $d x$ and long dimension $\&$ parallel to the tube axes. Let $F_{d x, S}(G)$ be the shape factor of this strip to the sky through a particular gap $G$. Then the total view factor of the strip to the sky through all gaps is 


$$
F_{d x, S}={ }_{G}^{\Sigma} F_{d x, S}(G)
$$

where the sum includes all gaps $G$ through which diffuse light can reach the strip $d x$. The back reflected radiation per unit of absorber tube cross section area is therefore

$$
d S_{d R}=\pi \rho S_{d} F_{d x}, S^{d F_{T}}, d x
$$

where $\mathrm{dF}_{T, d x}$ is the shape factor of a given absorber tube to the strip $d x$ and $\rho$ the reflectance of the screen for diffuse radiation, here assurned equal to that for the beam radiation. Integrating over all strips $d x$,

$$
S_{d R}=\pi_{\rho} S_{d} \int_{\text {screen }} d F_{T, d x} F_{d x, S} \equiv \pi \rho S_{d} F_{T P} F
$$

where $F_{T P}$ is the shape factor from an absorber tube to the backing screen and the function $\bar{F}$ is defined as

$$
\bar{F}=\frac{1}{F_{T P}} \int_{\text {screen }} d F_{T, d x} F_{d x, S}
$$

For a large enough screen, it is a good approximation to take $F_{T P} \approx F_{T S}$, so that the total diffuse insolation on an absorber tube becomes

$$
S_{d T}=\pi F_{T S} S_{d}(1+\rho \bar{F})
$$

The factor $F_{T S}$ is readily evaluated by Hottel's crossed and uncrossed string method [3] and is found to vary with tube spacing $d$ between the limits $0.27 \leq F_{T S} \leq 0.5$. The lower limit corresponds to close packed tubes $\left(d=D_{6}\right)$, while the upper limit corresponds to infinitely spaced tubes. The function $\bar{F}$ defined by Eq. (27) depends on the shape factors $F_{d x}, S(G)$ through Eq. (24). Each $F_{d x, S}(G)$ gives the intensity distribution of light on the screen resulting from diffuse radiation passing through a gap $G$, and by using the crossed and uncrossed string method [3] it can be shown that in general, 


$$
\begin{aligned}
& F_{d x, S}(G)=\frac{1}{2}\left[F_{+}(G)+F_{-}(G)\right] \\
& F_{ \pm}(G)=\frac{(d / 2 \pm x)\left[(d / 2 \pm x)^{2}+D_{B}^{2}-D_{6}{ }^{2} / 4\right]^{2 / 2}-D_{B} D_{6} / 2}{(d / 2 \pm x)^{2}+D_{B}{ }^{2}}
\end{aligned}
$$

where the origin of $x$ is at the center of the gap.

When the collector tilt $s$ is other than zero, ground reflections also contribute to the diffuse insolation on the tube array. Such reflections can in some cases be a significant component of the total insolation on the array, and are readily taken intu account with the relation [2]

$$
S_{d T}=\pi F_{T S}(1+\rho \bar{F})\left[S_{d}\left(\frac{1+\cos s}{2}\right)+\rho_{G}\left(S_{d}+S_{B H}\right)\left(\frac{1-\cos s}{2}\right)\right]
$$

where $\rho_{G}$ is the reflectance of the ground.

\section{EFFECT OF DESIGN PARAMETERS ON COLLECTOR PERFORMANCE}

A. Performance Index $F_{R} / F^{\prime}$ Most of the design and operating characteristics of the collector are contained in the performance index $F_{R} / F^{\prime}$ defined by Eq. (7), Section II.A. The performance index is a function of two dimensionless quantities $\lambda_{1}$ and $\lambda_{2}$ defined by Eqs. (31) and (32) below.

$$
\begin{aligned}
& \lambda_{1}=\omega_{2} / \omega_{1}=\left(1+4 U_{1} P_{1} / U_{L} P_{L} F^{\prime}\right)^{1 / 2} \\
& \lambda_{2}=\omega_{2} \xi_{1}=\lambda_{1} U_{L} A_{L} F^{\prime} / 2 \dot{m} C_{p}
\end{aligned}
$$

The quantity $\lambda_{1}$ is termed the thermal coupling parameter. This term describes the effect of the heat transfer from the annulus to the delivery tube fluid on the performance of the collector. $\lambda_{2}$ is called the loss/flow parameter since it depends on the ratio of the collector loss coefficient to the mass flow rate of the working fluid: Notice that $\lambda_{2}$ is also a 
function of $\lambda_{1}$.

Figure 6 is a plot of several level curves of $F_{R} / F^{\prime}$ for various values of the parameters $\lambda_{1}$ and $\lambda_{2}$. The performance index can always be improved (made closer to 1) if the thermal coupling parameter $\lambda_{1}$ is made to approach a value of 1 by insulating the delivery tube. In practice this is expensive to do and is made unnecessary by manipulating the loss/flow parameter $\lambda_{2}$.

In the performance index definition if the term $\omega_{2} \xi_{2}$ is small, then $\cosh \omega_{2} \xi_{1} \simeq 1$ and $\sinh \omega_{2} \xi_{1} \simeq \omega_{2} \xi_{1}$. So,

$$
F_{R} / F^{\prime} \times 1 /\left(1+U_{L} A_{L} F^{\prime} / 2 \dot{i} C_{p}\right)
$$

Thus, as long as $\omega_{2} \xi_{1}$ is small, $\left(F_{R} / F^{\prime}\right)$ does not depend on the thermal coupling term $\lambda_{1}$ no matter what its value. In principle, this approximation can always be made valid by increasing the mass flow rate $\dot{m}$ to offset a large value of the thermal coupling parameter. In practice with the present collector design dimensions and loss coefficient and water as the working fluid, the thermal coupling term $\lambda_{1}$ cannot be made larger than about 15 . If a limit $\lambda_{2} \leq .3$ is established for the approximation to hold, then $\dot{m} \geq 2.5 \mathrm{~kg} / \mathrm{hr}$. per collector tube. This minimum flow rate yields a temperature rise of $15^{\circ} \mathrm{C}$ from $66^{\circ} \mathrm{C}$ at $\mathrm{S}_{\text {eff }}=946$ watts $/ \mathrm{m}^{2}$ in one juss through the collector tube. Under these operating conditions $F^{\prime}=.995$ and $F_{R}=.974$. Higher flow rates improve $F_{R}$ but decrease the temperature rise in one pass.

Figure 7 shows the effect of changing the flow rate on the temperature distribution along the delivery tube and annulus. Seff again is 94.6 watts $/ \mathrm{m}^{2}$ and $T_{\text {in }}=20^{\circ} \mathrm{C}$. The flow rates are $4.5 \mathrm{~kg} / \mathrm{hr}$. and $1 \mathrm{~kg} / \mathrm{hr}$. per collector tube. At the $4.5 \mathrm{~kg} / \mathrm{hr}$. flow rate most of the temperature rise in the collector takes place in the annulus. This is in agreement with the performance index analysis that says the thermal coupling is unimportant 
at a sufficiently high flow rate. At $1 \mathrm{~kg} / \mathrm{hr}$., the thermal coupling is large with a large temperature rise in the delivery tube. As can be seen from Fig. 7, the collector is losing heat at a higher temperature than the temperature delivered at the outlet of the collector. This is not a particularly good operating condition even though $F_{R}$ for this case is .925. The same temperature rise can be obtained by passing the fluid through several collector tubes in series at a higher flow rate. Engineering trade-offs can te made on tine basis of flow rate and temperature rise reflected in the performance index $F_{R}$ versus pumping power and capacity required to push the fluid through the collector.

B. Loss Coefficient $U_{L}$ The loss coefficient $U_{L}$ defined by Eq. (8) in Section II.B. is plotted in Figure 8 for two extreme ambient temperature conditions. The same data is presented in Tables 2 and 3 which include the intermediate surface temperatures $T_{5}$ and $T_{6}$. Several conclusions can be drawn from the data in Figl 8 and Tables 2 and 3 . First, since $U_{L}$ varies from 0.3 to 1.4 watts $/ \mathrm{m}^{2}{ }^{\circ} \mathrm{C}$ in the potential operating range of the collector, the collector can be described as having a very low loss coefficient. Secondly, $U_{L}$ decreases somewhat with decreasing ambient temperature because the value of $U_{L}$ is controlled by the radiation loss from the collector. This is important in heating season applications where the ambient temperature is low.

Third, $U_{L}$ increases gradually with increasing operating temperatures. As discussed in Section III.A, it is undesirable to operate the collector at a large temperature gain in one pass because of the decrease in performance index. If the collector is operated at a modest temperature gain, $U_{L}$ can be treated as a constant over this temperature range. Thus, linear theory in heat balance calculations can be used. $U_{L}$ has been treated this way in our computations. 
Fourth, the heat loss through the collector is so small that the cover tube temperature is within a few degrees of ambient temperature even at high absorber temperatures. This means that $U_{L}$ is most strongly dependent on the radiation loss coefficient $h_{1}$.

Last, because of the low loss coefficient, gases as well as liquids can be used as the working fluid. Even though the heat transfer from the absorber tube to the working fluid is much poorer with gases than with liquids, the consequent rise in absorber surface temperature dues not increase the heat loss appreciably. Air is a particularly attractive working fluid because it decreases the rooftop weight of the collertor and does not have any spill or lcak problems.

C. Insolation and Tube Spacing The components of insolation discussed in Section II.C. can be combined into a total effective insolation $\mathrm{S}_{\text {eff }}$ which is used in Eq. (1) and is given by

$$
S_{e f f}=S_{B H}\left(R_{T}+R_{p} \rho \frac{W}{D_{4}}{ }_{i}^{\Sigma} F_{i T}\right)+S_{A} \pi F_{T S}(1+\rho \bar{F})
$$

where use has been made of Eqs. (12), (18), and (28). For simplicity, Eq. (34) and the discussion that follows assume that the component of insolation due to ground reflections is equal to $s_{d}$, the uniform component from the sky dome; the effect of this assumption is the same as if the tilt s were taken equal to zero in Eq. (30), and does not materially affect the conclusions that follow.

The factors $R_{T}, W, F_{i T}, F_{T S}$, and $\bar{F}$ in Eq. (34) all depend on tube spacing $d$, and in each case it is found that the energy available to the tubes increases as $d$ increases. In the case of $R_{T}$, the dependence on tube spacing enters through the shading factor $g(\omega)$ defined by $E q$. (11) and used in approximated form in Eq. (5). The ratio $S_{B D} / S_{B O}$ from Eq. (13) is shown in Fig. 9 for an equinox day and several different tube spacings 
d. Figure 10 sinows this ratio for the winter and summer solstices at latitude $L=40^{\circ} \mathrm{N}$ and for collector tilts of $52^{\circ}$ and $28^{\circ}$, favoring the heating and cooling seasons respectively. In Fig. 10 a tube spacing $d=.2 D_{6}$ is assumed. Both Fig. 9 and 10 illustrate the fact that the cylindrical symmetry of the tubes allows nearly all of the bean component to be intercepted in the early morning and late afternoon if the spacing between tine tubes is large enough. The beam component incident on a flat surface at those times is generally low because of tie cosine intercept factor, and consequently the operating efficiency is reduced below that for solar noon. The fact that an array of spaced tubes can make efficiont use of the available light over most of a day means that the overall operating efficiency of a tubular array should be judged on a daily basis rather than on an instantaneous basis, as is frequently done with flat plate collectors.

The factors $W$ and $F_{i T}$ give rise to the dependence of the back-reflected beam component $S_{B R}$ on tube spacing. Figure 11 shows the ratio $S_{B R} / \rho S_{B O}$ as a function of $\omega$ for four different tube spacings $d$. These plots are for an equinox day with the plane of the screen tilted at $s=L$, and the screen distance has been taken as $D_{B}=3 D_{6} / 2$. It is apparent that the backreflected component $S_{B R}$ increases with $d$, and in general can be an appreciable fraction of $S_{B O}$.

Figure 12 shows the shape factor $F_{d x, S}(G)$ from Eqs. (24) and (29) for $d=2 D_{6}$ and $D_{B}=3 D_{6} / 2$, the values used with present Owens-Illinois collector arrays. Also shown in Fig. 12 is the sum $F_{d x}, S$, which is scen to be nearly constant along the screen. This behavior is typical of other tube - spacings of interest, and greatly facilitates the evaluation of the function $\bar{F}$ defined by $E q .(27)$. Table 4 shows several average values of $\bar{F}$ determined by using plots like Fig. 12, and also indicates the maximum positive and negative excursions from these values. The largest excursions occur for 
small spacings, and amount to about. $15 \%$ of tiie average value. For larger spacings, the excursions are typically under $5 \%$.

The effect of tube spacing on the overall thermal performance of a collector array is best illustrated by considering the energy outputs expected from arrays with different tube spacings uncier different operating conditions. Equation (34) gives the total insolation on a tube in an array with spacing $d$, while Eq. (1) gives the rate at which the tube produces energy. If $S_{p}=R_{P} S_{B H}+S_{d}$ is the insolation in the plane of the backing screen and $d$ the center-to-center distance between tubes, one can define an array efficiency on an active installed area basis as follows:

$$
\begin{aligned}
n(\omega) & =Q_{u} / \ell d S_{p} \\
& =\frac{D_{4}}{d} \frac{F_{R}}{S_{p}}\left[\alpha \tau S_{\text {eff }}-\pi U_{L}\left(T_{\text {in }}-T_{a}\right)\right]
\end{aligned}
$$

Figure 13 shows $n(\omega)$ plotted against the reduced variable $\left(T_{\text {in }}-T_{a}\right) / S_{p}$ for an array in which $d=2 D_{6}$ and $D_{B}=3 D_{6} / 2$. For comparison, a similar curve for a two cover non-selective flat plate collector is also shown [4]. In arriving at these curves the following assumptions have been made. An equinox day has been selected at $40^{\circ} \mathrm{N}$ latitude, and for simplicity the collector tilt is taken to be $s=40^{\circ}$., Losses from the tubular array are assumed to be entirely radiative and characterized by an emittance of $\varepsilon=0.07$; the absorptance is $\alpha=0.86$, the transmittance $\tau=0.92$, and the backing screen reflectance $\rho=0.85$. These numbers represent average values inferred from optical measurements on the selective coating, cover tube glass, and backing screen respectively. In the case of the backing screen, the reflectance is that of an outdoor white paint on plywood. 
In order to evaluate $S_{\text {eff }}$, a day was chosen on which the total radiation on a horizontal surface was $20 \times 10^{3} \mathrm{~kJ} / \mathrm{m}^{2}$ day. The methods of Liu and Jordan [5] were used to divide this total into hourly beam and diffuse components of insolation, with the results shown in Table 5.

The most striking feature of Fig. 13, aside from the low loss coefficient, is the fact that $n(\omega)$ increases with hour angle $\omega$. This behavior is unlike that of flat plate collectors, whose efficiencies are generally independent of $\omega$, and results primarily because of the back-reflected beam component and the symmetry of the tubes to the beam component of insolation.

Figure 13 suggests that a better figure of merit than $n(\omega)$ for evaluating the thermal performance of a tubular array is the daily efficiency $n_{D}$, defined as

$$
\eta_{D}=\frac{\Sigma S_{p} n(\omega)}{\Sigma S_{p}}
$$

where the sums are over the hourly insolation values for a day. The quantity $n_{D}$ has been calculated for various tube spacings and operating temperatures, under the same assumptions used in generating Figure 13. The results are shown in Fig. 14. It is evident that the largest energy output is obtained for $d=D_{6}$ (i.e., close packed tubes) when the collector is operated near ambient temperature. At higher operating temperatures, however, maximum efficiencies are obtained at successively greater spacings. Thus, at $T_{\text {in }}-T_{a}=111^{\circ} \mathrm{C}$, maximum energy output is obtained for $d=1.5 D_{6}$, while at $T_{\text {in }}-T_{a}=167^{\circ} \mathrm{C}$, the maximum occurs at $d=2 D_{6}$. The basic reason for this behavior is that, on the one hand, the greatest amount of radiation is intercepted, per unit of installed area, when the spacing is small. On the other hand, the ratio of energy available per tube to energy lost by the tube increases with 
spacing, so that each tube can produce more useful energy as the spacing is increased.

The increase in the ratio of energy intercepted to energy lost by a tube with tube spacing also means that an array becomes capable of operating at higher temperatures as the spacing is increased. This fact is emphasized by Figure 15, in which the results of Figure 14 are plotted in a different form. This Rlot is similar to Figure 13, except that $n_{D}$ instead of $n(\omega)$ is plotted on the ordinate while the reduced variahle on the abscissa contains the daily total insolation rather than $\mathrm{S}_{\mathrm{p}}$. Although these results are based only on a single daily total insolation $\Sigma S_{p}=24.5 \times 10^{3} \mathrm{KJ} / \dot{m}_{0}^{2}$, calculations indicate that the curves can be applied to other total insolations with only minor error. The error, which is found to be only a few percent of the efficiencies shown in Figure 15, arises mainly from the fact that beam and diffuse insolation are distributed differently for different daily totals.

An analysis of the effect of screen distance $D_{B}$ on array efficiency can be made by methods which are similar to those used to analyze tube spacing. The results show, for example, that for $d=2 D_{6}$ the optimum screen distance is $D_{B}=3 D_{6} / 2$ for all operating temperatures of interest. More important, however, is the fact that these resulis indicate that array efficiency is insensitive to $D_{B}$ over rather wide limits. In fact, for $0.5 \leq D_{B} / D_{6} \leq 4$, the efficiency remains constant to within $10 \%$. Figure 14 shows that array efficiency also varies rather slowly with tube spacing. This insensitivity of efficiency to both $D_{B}$ and $d$ means that precise alignment of the tubes is not essential to good collector performance, a fact which makes installation of collector arrays simpler. In. addition, it offers array design flexibility for those situations in which architectural or other considerations might call for a variable 
spacing and backing dịtance in the same collector system.

It should be emphasized that while figure 14 gives the optimum tube spacings under various conditions from the thermal performance point of view, economic considerations may dictate altogether different spacings for overall optimum system cost effectiveness. The array cost per unit of installed area can generally be expected to decrease with increased tube spacing since the hardware required decreases with increased spacing. If performance is viewed in terms of collector cost per unit of energy delivered, the optimum tube spacings are expected to be somewhat larger than those shown in Figure 14.

\section{EXPERIMENTAL TESTS OF COLLECTOR ARRAYS}

Experimental tests have been made both indoors [6] and outdoors on a variety of tubular collector arrays using air, water, and ethylene glycol - water mixtures as the heat transfer fluid: These tests were at ambient temperatures ranging from about $-10^{\circ} \mathrm{C}$ to $25^{\circ} \mathrm{C}$, and at operating temperatures ranging from ambient temperature up to about $130^{\circ} \mathrm{C}$. The tube spacing in all arrays was fixed at $d=2 D_{6}$, and the screen distance was $D_{B}=3 D_{6} / 2$. In let and outlet temperatures were measured using Type $T$ thermocouples inserted into the fluid stream at the ends of the manifold. For liquids, a rotameter was used to indicate flow rate, with more precise values being obtained by timing the accumulation of fluid in a graduated cylinder. An Eppley model 645-48 pyranometer mounted in the tilt plane of the collector was used to monitor total insolation.

Equation (34) evaluated for $d=2 D_{6}$ and $D_{B}=3 D_{6} / 2$ would give $S_{\text {eff }}$ for the arrays tested if the diffuse component $S_{d}$ were distributed uniformly over the sky dome; however, outdoor tests were usually made on clear days, when $S_{d}$ was probably confined to the region of the solar disk, and indoor tests were made with a simulator, which produces 
no diffuse component. It should, therefore, be a valid approximation for all tests to write $S_{\text {eff }}$ in the form

$$
S_{\text {eff }}=S_{H}\left[R_{T}+R_{p} \rho \Delta\left(2-\frac{1}{\cos \omega}\right)\right]
$$

where $S_{H}$ is the total insolation on a horizontal surface and $\Delta$ is given by Eq. (22). Equations (37) and (35) can then be used to calculate instantaneous efficiencies for comparison with the test data.

The details of the indoor simulator tests have been reported elsewhere [6]. The results are reproduced in Figure 16a, along with calculated curves based on the collector parameters shown in Table 6 . The data clearly show the dependence of $n(\omega)$ on hour angle $\omega$ predicted by the collector model. In arriving at the calculated curves, it is assumed that the cover tube transmittance is $\tau=0.92$; the value $\rho \Delta=0.5$ is inferred from the intercept efficiencies at the three angles, and the value $U_{L}=$ 1.0 watt $/ \mathrm{m}^{2}{ }^{\circ} \mathrm{C}$ from the slope of the data. This value of $U_{L}$, the flow rate ( $34 \mathrm{~kg} / \mathrm{hr} . \mathrm{m}^{2}$ of installed area), and assumed values for the heat transfer coefficients can then be used in Eq. (7) to determine the $F_{R}$ shown. The absorptance $\alpha=0.86$ is then the value that best fits the data.

Equation (22) and Fig. 11 indicate that a value of $\rho \Delta=0.6$ is to be expected if $\rho=0.85$. Whether the measured value of 0.5 is lower because of a lower reflectance or because end effects have been neglected in the calculated value of $\Delta$ is not certain; in any event, the agreement is considered to be satisfactory.

Optical and thermal testing of the tubes used in this particular test unit suggest an average coating emittance of $\varepsilon=0.09$. The data, on the other hand, suggest an effective emittance of $\varepsilon=0.12$ if it is assumed that about $10 \%$ of the experimental $U_{L}$ is due to losses in the manifold. The difference in these values is believed to be due to uncoated areas 
near the ends of the absorber tubes and to coating scrapes along the lengths of the tubes. These scrapes occurred during the early experimental assembly of the test unit and have been eliminated on present tubes. Indeed, since the emittance of uncoated glass is about 0.9 , less than $5 \%$ of the absorber tube area need be scraped or uncoated to account for the above difference in effective emittance.

Figure 16b shows the results of outdoor tests made at Toledo, Ohio $\left(L=42^{\circ} \mathrm{N}\right)$ on an array consisting of eight tubes. The tube axes were oriented north-south and the collector tilt. was $s=51^{\circ}$. The data summarize tests made during the period January 23, 1975 to February 14, 1975 when the declination $\delta$ varied from $-20^{\circ} \mathrm{C}$ to $-14^{\circ} \mathrm{C}$ and the ambient temperature from $-10^{\circ} \mathrm{C}$ to $+10^{\circ} \mathrm{C}$. Wind speed was not recorded. Pure ethylene glycol was used as the heat transfer fluid at all temperatures (up to $130^{\circ} \mathrm{C}$ ). The average flow rate was about $25 \mathrm{~kg} / \mathrm{hr}^{2} \mathrm{~m}^{2}$. Also shown are calculated curves for $\omega=0^{\circ}$ and $\omega=40^{\circ}$, based on the parameters shown in Table 6 . In this case the angular dependence of $n(\omega)$ is not as sharply defined by the data as in Figure 16a, but it is reasorable to suppose that this fact is due largely to the variability of outdoor conditions, which are not as well controlled as indoors. 'In any event, the calculated curves are consistent with the data. For these tests the parameter $\rho \Delta=0.73$ is reasonably consistent with the expected value of $\rho \Delta=0.6$. As in the case of the indoor tests, the difference could be due either to screen reflectance or the neglect of end effects in the calculated value. The loss coefficient $U_{L}$ is somewhat lower than for the unit tested indoors, the improvement probably being the result of the elimination of coating scrapes on the tubes used in the present unit. If $10 \%$ of the experimental $U_{L}$ is assigned to manifold losses, it is found that the effective emittance is $\varepsilon=0.09$, as compared with an expected emittance of $\varepsilon=0.07$ based on optical tests of the 
coating. The difference is probably caused in part by the fact that, even though the tubes had no coating scrapes, the ends of the absorber tubes were still uncoated and therefore, had the emittance of bare glass. Since recent improvements in coating procedure now allow the entire absorber tube to be covered, future collector arrays are expected to have even lower loss coefficients.

\section{TRANSIENT BEHAVIOR}

The general time and space dependent solution to Eqs, (2) and (3) is still under investigation. However, a solution has been obtained for the case where thermal coupling between the two fluid passages is unimportant. This situation corrcsponds to the operaling conditions already discussed in Section III. as being desirable for good performance.

If the thermal coupling in Eqs. (2) and (3) is neglected anc the boundary conditions are assumed to be

$$
T_{1}(0, \hat{t})=T_{\text {in }}(\hat{t}) \text { and } T_{1}\left(\xi_{1}, \hat{t}\right)=T_{2}\left(\xi_{1}, \hat{t}\right)
$$

it can be shown that for $\hat{t}>(a+1) \xi_{1}$, when start-up effects are no longer important,

$$
\begin{aligned}
Q_{u} & =\dot{m}_{p}\left\{T_{0}(0, \hat{t})-T_{i n}\left[\hat{t}-(a+1) \xi_{1}\right]\right\} \\
& =F_{R}(1) A_{C}\left\{a \tau\left\langle S_{e f f}\right\rangle-U_{L} \frac{A_{L}}{A_{C}}\left[T_{i n}\left[\hat{t}-(a+1) \xi_{1}\right]-T_{a}\right]\right\}
\end{aligned}
$$

Here, $F_{R}(1)$ is given by $\mathrm{Eq}$. (7) with the coupling parameter $\lambda_{1}$ equal to one and $\left\langle\mathrm{S}_{\text {eff }}\right\rangle$ is defined by

$$
\left\langle S_{e f f}\right\rangle=\frac{F^{\prime}}{F_{R}(1) \xi_{1}} \int_{0}^{\xi_{1}} d \theta S_{e f f}(\hat{t}-\theta) e^{-\left(1-F^{\prime}\right) \theta}
$$


The difference between the times at which the inlet and outlet temperatures are evaluated is equal to the time required for an element of fluid to move through the collector. The quantity $\mathrm{S}_{\text {eff }}$ is a weighed average of the effective insolation over the time that the fluid is in the annulus. The time delays are of interest in the tubular collector because under normal or "good" operating conditions, an element of water can be resident in the collector for about thirty minutes, and this situation has important implications for the control characteristics of the collector. Equation (39) is an exact solution for a well-insulated delivery tube or a single pass collector, and should be a good approximation for the Owens-11linois tubular collector as long as thermal coupling effects are not significant. In fact, preliminary tests during which $T_{\text {in }}$ was allowed to vary with time indicate that Eq. (39) properly accounts for time (indicate that Eq. (39) properly accounts for time) delay effects.

\section{DISCUSSION}

The Owens-Illinois, Inc. SunPak ${ }^{T M}$ solar collector described in this paper incorporates several desirable collector features. Collector evacuation and selective coating produce an extremely low heat loss coefficient $U_{L}$. Some aspects of the low loss coefficient are discussed in Section III.B. Further, the low heat loss enables the collector to operate with good efficiency at temperatures high enough to drive existing heating and cooling devices presently using fossil fuel energy sources. This means that retro-fitting solar energy to existing installation is now feasible. In addition, present design heating and cooling devices can be used without de-rating their capacities due to inadequate temperatures obtained from the collector. Alternatively, and possibly more important, the SunPak ${ }^{\mathrm{TM}}$ collector can operate with good efficiency at more moderate temperatures on days when the insolation is low. In fact, 
for a collector temperature of $65^{\circ} \mathrm{C}$ and an ambient temperature of $0^{\circ} \mathrm{C}$, only 80 watts $/ \mathrm{m}^{2}$ of insolation are required in order to obtain usefui energy from the collector.

The performance index $\left(F_{R} / F^{\prime}\right)$ described in Section III.A. can be made greater than .9 for all applications envisioned to date. The thermal coupling between the delivery tube and the annulus does adversely affect the performance index if the operating conditions are not carefully examined. However, suitable flow rates and array configurations can be designed so that the thermal coupling becomes negligibile.

As discussed in Section III.C., the effective insolation on a tube, $S_{\text {eff }}$, has a time dependence that differs from that of most collectors. Because of the tube-to-tube spacing, the collector intercepts direct beam radiation uniformly for eight hours with the present collector design. In addition, the back reflective screen permits the recovery of about fifty per cent of the radiation that falls between the tubes. This means the instantaneous efficiency $n(\omega)$ as usually defined increases toward the beginning and end of the day for a south facing array in the northern hemisphere. As a consequence, the collector array performance cannot be realistically evaluated on the basis of instantaneous efficiency, but rather must be judged on the basis of efficiency or energy output over periods no shorter than a day.

The insensitivity of collector efficiency to operating temperature, ambient temperature, and wind speed has already been mentioned. An impor$\tan$ consequence is flexibility in system design, since temperature conditions can vary over rather wide limits with no serious degradation of collector performance. This insensitivity also means that the collector can operate with air as the heat transfer fluid, with nearly the same efficiency as if a liquid were used. Because of its low film coefficients, 
air usually imposes a severe penalty on flat plate collectors by causing the absorber surface to run hotter than with a liquid. In the case of the evacuated tubular collector, the absorber surface runs hotter than with a liquid, but figure 16 shows that no significant decrease in efficiency will result. No modification of the basic tubular collector elements is necessary for operation with air. All that is necessary, in fact, is a larger delivery tube and a different manifolding system designed to give the proper air pressure drops through the collector array. Preliminary testing of air operated tubular arrays at the Owens-Illinois test site confirms that the performance is essentially as good as with a liquid heat transfer fluid.

Although not all of the predictions of the collector model developed in this paper have been verified by direct test data (for example, arrays with tube spacings other than $d=2 D_{6}$ have not been tested,) it is believed that the data presented in Section IV. substantiate the most important features of the model. The tube spacing $d=2 \mathrm{D}_{6}$ used with present OwensIllinois collectors was selected on the basis of both thermal performance and cost-effectiveness of the collector. Figure 15 shows that for this spacing the collector is less efficient at low temperatures (or high insolations) than if the tubes were more closely spaced. While the tubes could be more closely spaced to give better thermal performance at low temperatures, performance at high temperatures (or low insolations) would suffer and it is not clear that the collector would be as cost effective.

Finally, the collector tube material, glass, is already known to have good weathering and chemical durability properties, assuring long life of the collector. The present production collector is sold as a unit consisting of the collector tubes and manifold.which has headers incorporated in it. The units can be installed by one man either on the rooftop or other collection site. No mechanical lifting equipment is required for 
installation. Large arrays can be built up from the individual units with little difficulty. 


\section{ACKNOWLEDGMENTS}

The authors would like to express their gratitude to K. L. Moan and $Y$. K. Pei, whose many efforts are primarily responsible for making the collector described in this paper a practical reality, and who offered many valuable suggestions in the preparation of the paper. They would also like to thank Profs. J. A. Duffie and W. A. Beckman for their comments and assistance throughout the collector development program. 
1. A. Whillier, Low Temperature Engineering Applications of Solar Energy, ASHRAE, New York (1967). "Design Factors Influencing Collector Performance."

2. J. A. Duffie and W. A. Beckman, Solar Energy Thermal Processes, John Wiley and Sons. Inc. New York (1974).

3. H. C. Hottel and A. F. Sarofim, Radiative Transfer, McGraw-Hill, Inc., New York. (1967).

4. F. F. Simon, "Status of the NASA-Lewis Flat-Plate Collector Tests wit'i a Solar Simulator," NASA TIMX-71658 (1975).

5. B. Y. H. Liu and R. C. Jordan, Solar Energy 4, 1, (1960); Solar Energy I. 53 (1963).

6. F. F. Simon, "Solar Collector Performance Evaluation with the NASA-Lewis Solar Simulator - Results for an All-Glass-Evacuated-Tubular Selectively. Coated Collector with a Diffuse Reflector," NASA TMX-71695 (1975). 


$$
\begin{aligned}
& \text { Delivery Tube I.D. }-D_{1}-9 \mathrm{~mm} \\
& \text { Delivery Tube 0.D. }-D_{2}-12 \mathrm{~mm} \\
& \text { Absorber Tube I.D. }-D_{3}-39 \mathrm{~mm} \\
& \text { Absorber Tube } 0 . \text { D. }-D_{4}-43 \mathrm{~mm} \\
& \text { Cover Tube } \quad \text { I.D. }-D_{5}-49 \mathrm{~mm} \\
& \text { Cover Tube } \quad \text { 0.D. }-D_{6}-53 \mathrm{~mm} \\
& \text { Active Tube Length }-\ell-1067 \mathrm{~mm}
\end{aligned}
$$

Subscripted parameter values in the body of the paper refer to the numbering scheme established here.

Table 1: Collector tube dimensions and subscript identification 

$\frac{\text { Loss Coefficient }}{\text { Watts }}$ $M^{2}-{ }^{\circ} \mathrm{C}$

\subsection{6}

0.303

0.321

0.340

0.360

0.381

0.402

0.425

0.449

0.473

$0: 499$

0.526

0.554

0.583

0.613

0.645

0.677

0.711

0.746

0.782

0.820

0.859

0.899

0.941

0.983

1.028

1.074

1.121

1.170

1.220
Absorber Temperature

${ }^{\circ} \mathrm{C}$

0.

10.0

20.0

30.0

40.0

50.0

60.0

70.0

80.0

90.0

100.0

110.0

120.0

130.0

140.0

150.0

160.0

170.0

180.0

190.0

200.0

210.0

220.0

230.0

240.0

250.0

260.0

270.0

280.0

290.0
Inside \& Outside Cover Temp.

${ }^{\circ} \mathrm{C}$

$-19.9$

$-19.8$

$-19.7$

$-19.6$

$-19.5$

$-19.4$

$-19.3$

$-19,2$

$-19.1$

$-18.9$

$-18.8$

$-18.6$

$-18.4$

$-18.2$

$-18.0$

$-17.7$

$-17.5$

$-17.2$

$-16.9$

$-16.6$

$-16.3$

$-15.9$

$-15.6$

$-15.2$

$-14.7$

$-1.4 .3$

$-13.8$

$-13.3$

$-12.8$

$-12.2$

Table 2: Loss coefficient $U_{L}$ for $T_{a}=-20^{\circ} \mathrm{C}$ 
$\frac{\text { Loss Coefficient }}{\text { Watts }}$ $M^{2}-{ }^{\circ} C$
Absorber Temperature

${ }^{\circ} \mathrm{C}$

50.0

60.0

70.0

80.0

90.0

100.0

110.0

120.0

130.0

140.0

150.0

160.0

170.0

180.0

190.0

200.0

210.0

220.0

230.0

240.0

250.0

260.0

270.0

280.0

290.0
Inside \& Outside Cover Temp.

${ }^{\circ} \mathrm{C}$

40.1

40.2

40.2

40.4

40.3

40.5

40.4

40.6

40.6

40.8

40.7

41.0

40.9

41.2

41.1

41.4

41.3

41.6

41.5

41.9

41.7

42.1

41.9

42.4

42.2

42.7

42.4

43.0

42.7

43.3

43.0

43.7

43.3

44.1

43.7

44.5

44.0

44.9

44.4

45.4

44.8

45.9

45.3

46.4

45.7

46.9

46.2

47.5

46.7

Table 3: Loss coefficient $U_{L}$ for $T_{a}=40^{\circ} \mathrm{C}$ 


\begin{tabular}{|c|c|c|}
\hline Spacingyd & & $\bar{E}$ \\
\hline$D_{6}$ & & 0 \\
\hline $1.5 D_{6}$ & 0.14 & \pm 0.02 \\
\hline $2 \mathrm{D}_{6}$ & 0.343 & \pm 0.013 \\
\hline $3 D_{6}$ & 0.799 & \pm 0.014 \\
\hline $4 D_{6}$ & 1.280 & \pm 0.014 \\
\hline
\end{tabular}

Table 4: Values of $\bar{F}[E q$. (27)] for different tube spacings $d$. 


$\begin{array}{lcccc} & \begin{array}{c}S_{B H} \\ \left(W / \mathrm{m}^{2}\right)\end{array} & \begin{array}{c}S_{B P} \\ \left(\mathrm{~W} / \mathrm{m}^{2}\right)\end{array} & \begin{array}{c}S_{B 0} \\ \left(\mathrm{~W} / \mathrm{m}^{2}\right)\end{array} & \begin{array}{c}S_{d} \\ \left(\mathrm{~W} / \mathrm{m}^{2}\right)\end{array} \\ \pm 1 / 2 & 606 & 792 & 798 & 174 \\ \pm 1-1 / 2 & 543 & 707 & 767 & 158 \\ \pm 2-1 / 2 & 442 & 577 & 726 & 139 \\ \pm 3-1 / 2 & 315 & 410 & 675 & 104 \\ \pm 4-1 / 2 & 155 & 202 & 527 & 66 \\ \pm 5-1 / 2 & 38 & 50 & 382 & 22 \\ \Sigma\left(S_{B H}+S_{d}\right)=19.9 \times 10^{3} \mathrm{~kJ} / \mathrm{m}^{2} \text { day } & & \\ \Sigma\left(S_{B P}+S_{d}\right)=24.5 \times 10^{3} \mathrm{~kJ} / \mathrm{m}^{2} \text { day } & \\ \text { Equinox day }(\delta=0) \text { at } \mathrm{L}=40^{\circ} \mathrm{N}, \mathrm{S}=40^{\circ}\end{array}$

Table 5: Hourly beam and diffuse insolation on equinox day 


\begin{tabular}{|c|c|c|c|c|c|}
\hline Test & $F_{R}$ & $\alpha$ & $\tau$ & $\rho \Delta$ & $\left(\mathrm{W} / \mathrm{m}^{2}{ }^{\circ} \mathrm{C}\right)$ \\
\hline $\begin{array}{l}\text { Indoors } \\
\text { (NASA LeRC) }\end{array}$ & 0.975 & 0.86 & 0.92 & 0.5 & 1.0 \\
\hline $\begin{array}{l}\text { Outdoors } \\
\text { (Owens-I1linois) }\end{array}$ & 0.98 & 0.85 & 0.92 & 0.73 & 0.85 \\
\hline
\end{tabular}

Table 6: Collector parameters derived from test data 


\section{Figure Captions}

Figure 1: Details of collector tube assembly.

Figure 2: Collector array at Owens-Illinois test site.

Figure 3: - Control volumes for heat balance of Eqs. (2) and (3).

Figure 4: Thermal loss network for collector tube assembly.

Figure 5: Geometry of a spaced tube collector array.

Figure 6: Performance index level curves for different coupling and loss-flow parameters.

Figure 7: Temperature rise along a single collector tube for two different fluid flow rates.

Figure 8: Dependence of the loss coefficient $U_{L}$ on absorber tube surface temperature and ambient temperature.

Figure 9: Dependence of $S_{B D}$ on time for different tube spacings.

Figure 10: Dependence of $S_{B D}$ on time at the winter and summer solstices. for two different collector tilts. A spacing $d=2 D_{6}$ is assumed.

Figure 11: Dependence of $S_{B R}$ on time for different tube spacings.

Figure 12: Shape factors $F_{d x, s}(G)$ for $d=2 D_{6}$. and $D_{B}=3 D_{6 / 2}$. The sum $F_{d x, s}$ is nearly constant across the screen.

Figure 13: Instantaneous efficiency of a two cover, nonselective flat plate collector and a south facing tube array with $d=2 D_{6}$. An equinox day and $s=L$ are assumed.

Figure 14: Dependence of daily efficiency of a tubular array on tube spacing for different operating conditions.

Figure 15: Dependence of daily efficiency of a tubular array on $\left(T_{i n}{ }^{-T_{a}}\right) / \Sigma S_{p}$ for different tube spacings.

Figure 16: Measured and calculated efficiencies of two tubular test arrays. (a) Data from NASA LeRC indoor simulator. (b) Outdoor data taken at Owens-I1linois test site. 


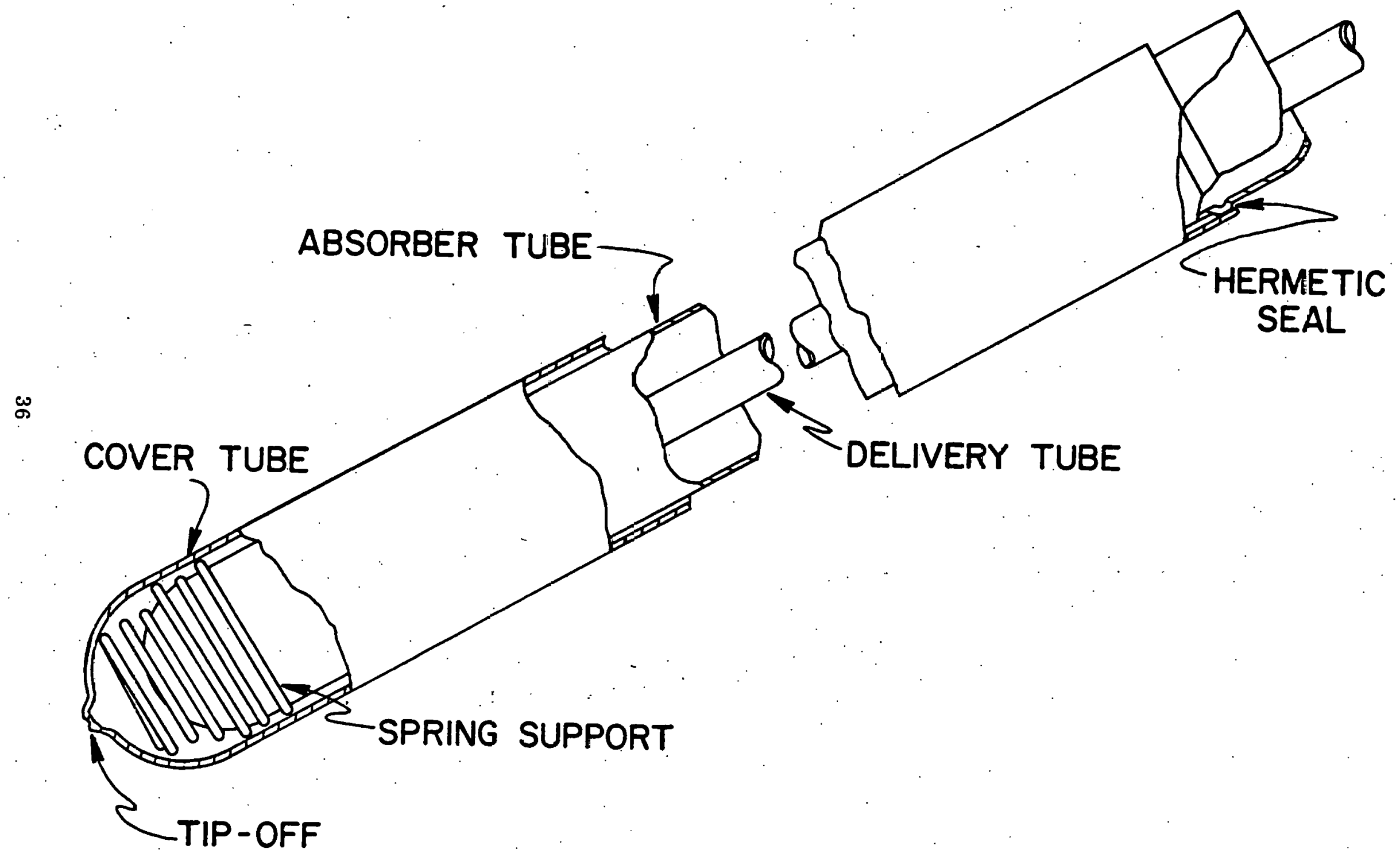

Figure 1 




Figure 2 




Figure 3 


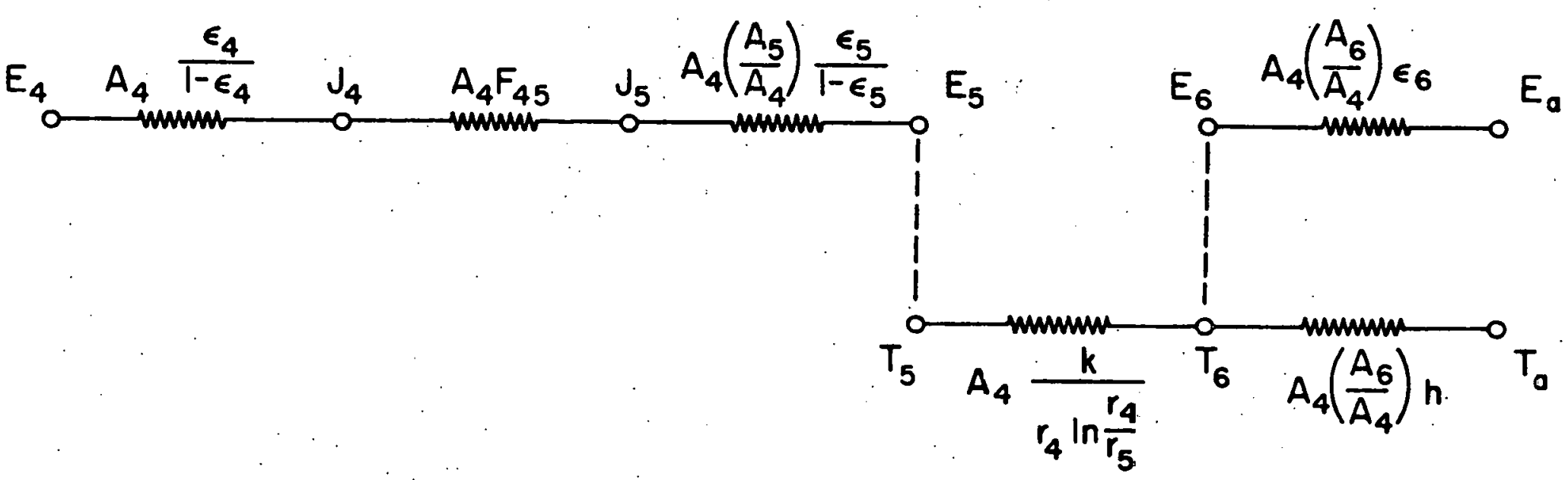

Figure 4 


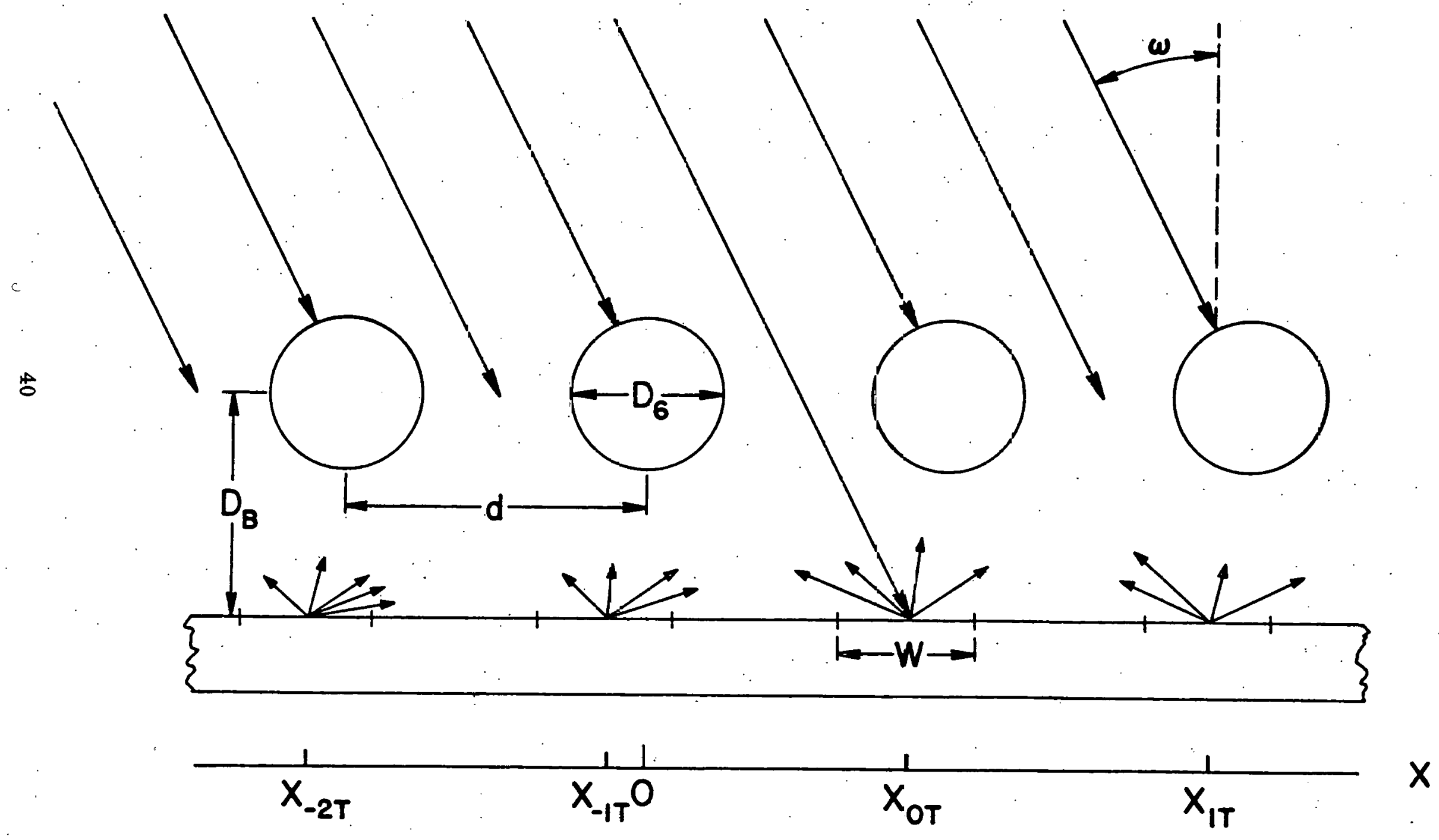

Figure 5 


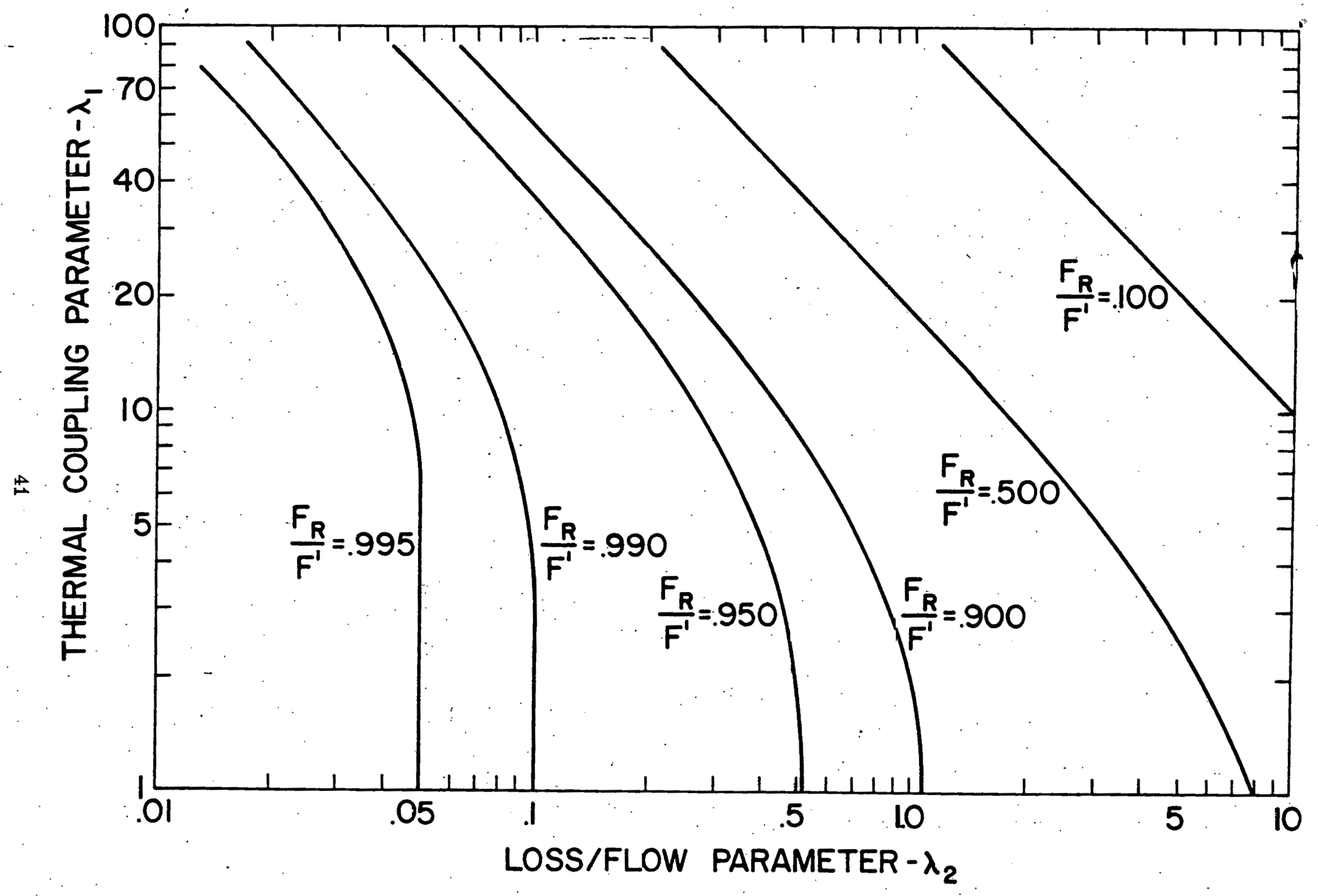

Figure 6 


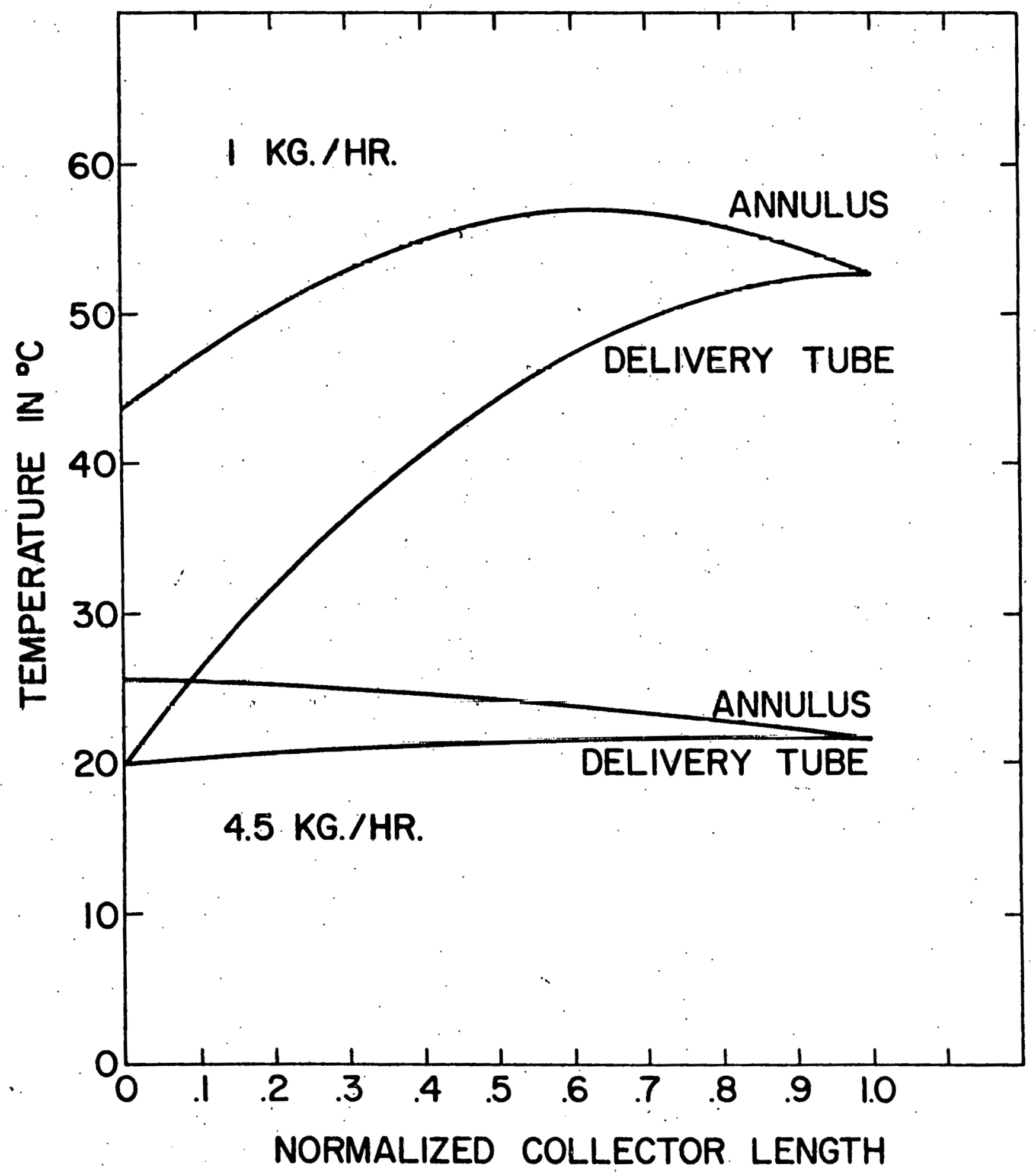




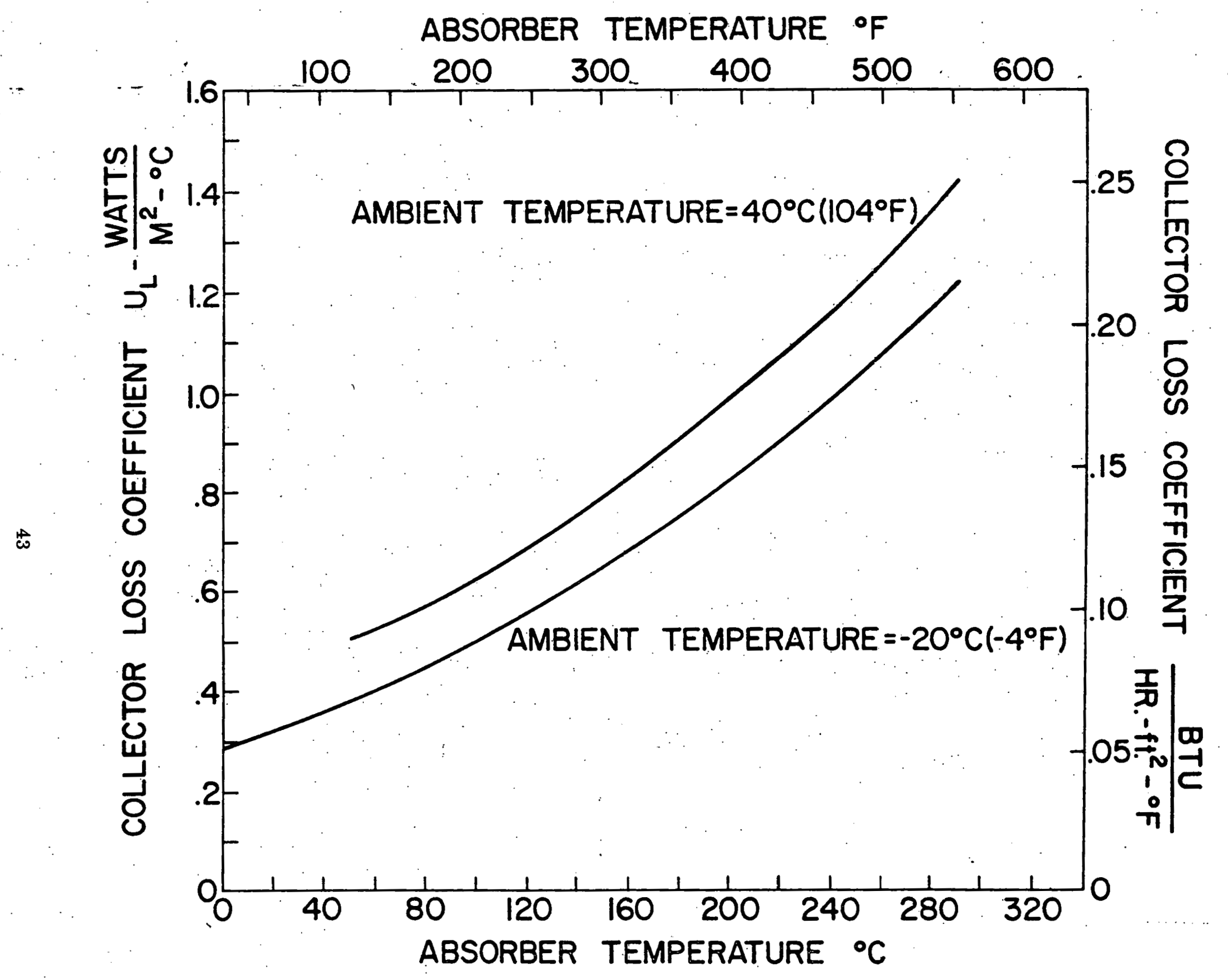

Figure 8 
本

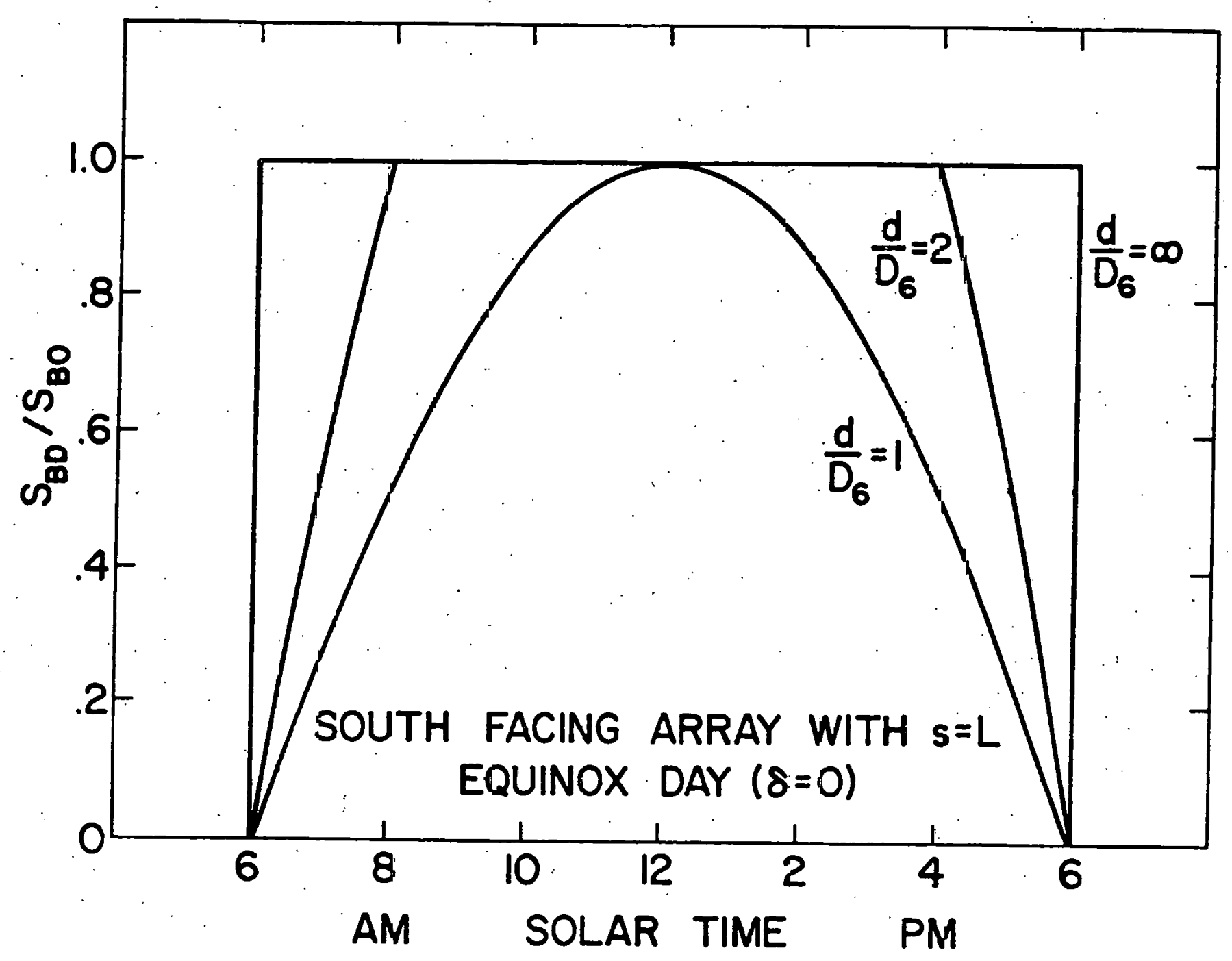

Figure 9 









Figure 11 


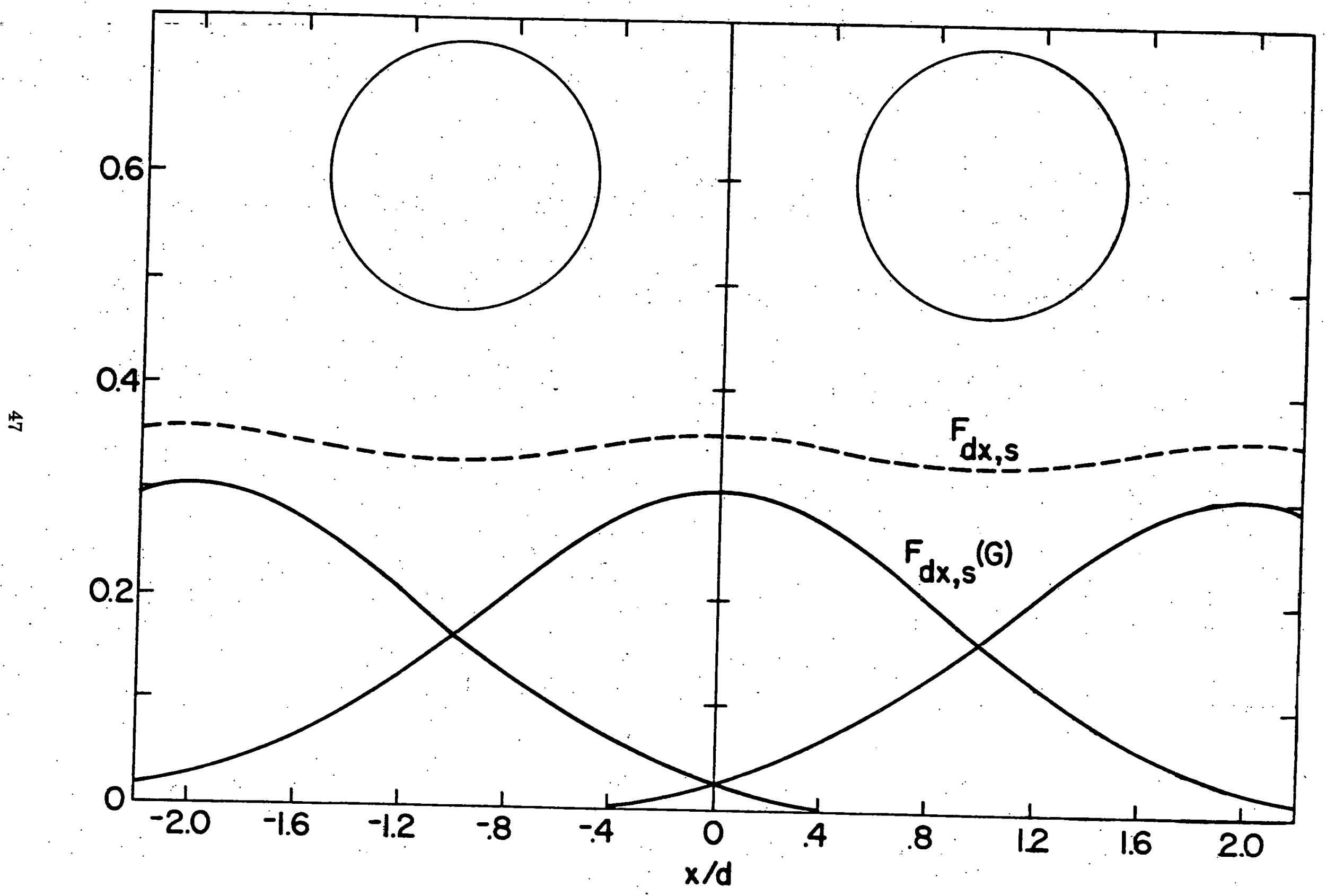

Figure 12 


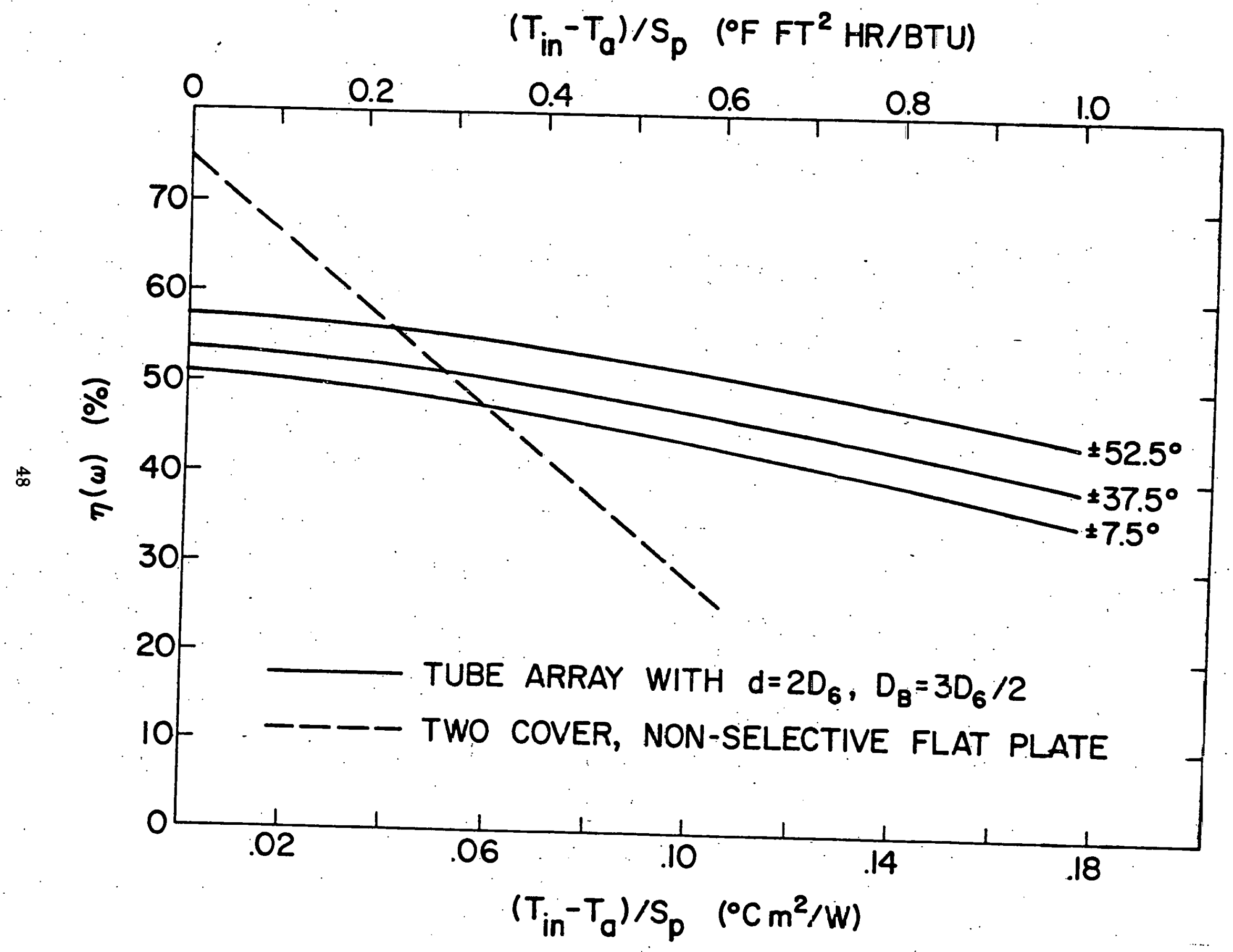

Figure 13 


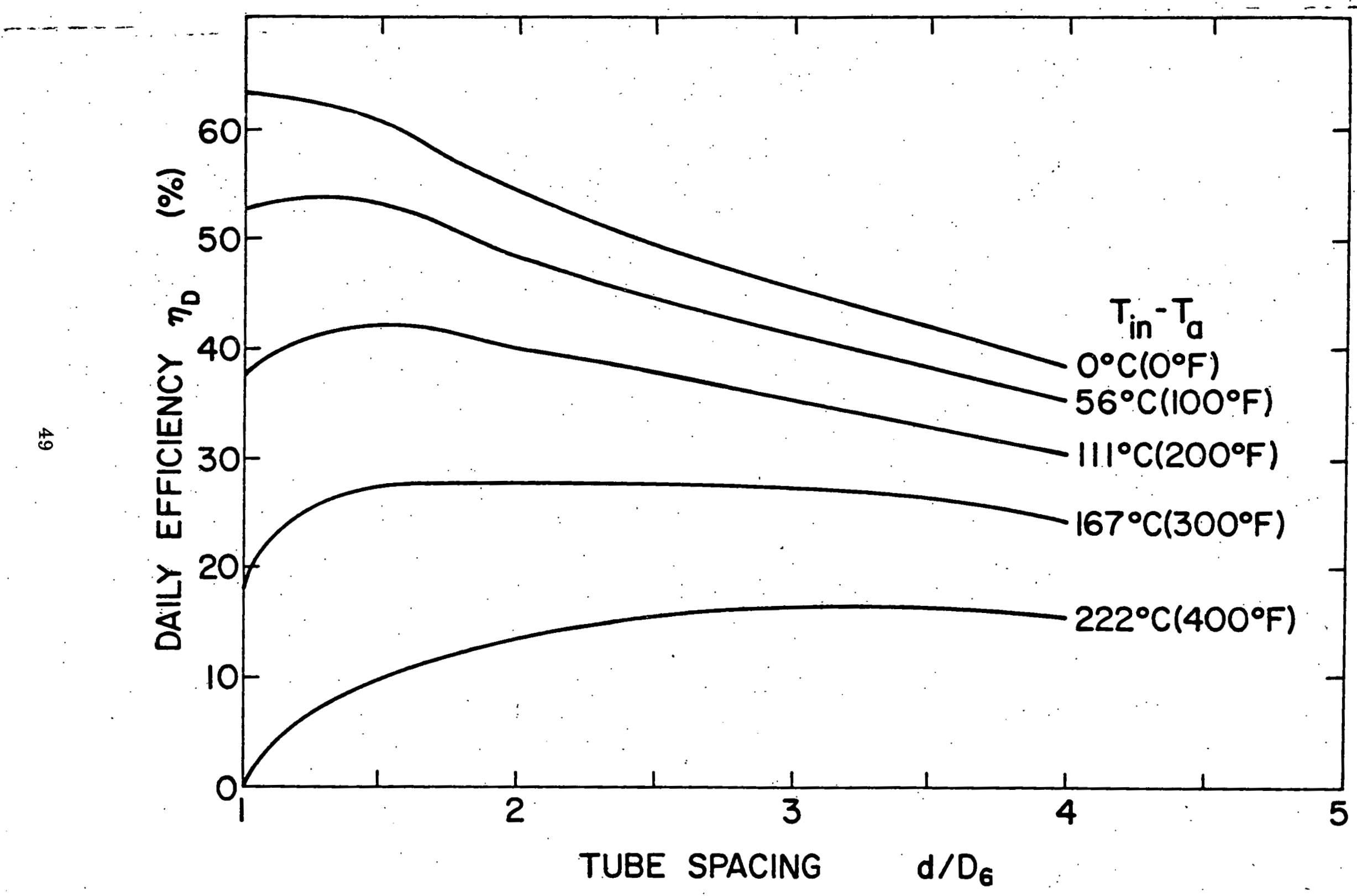




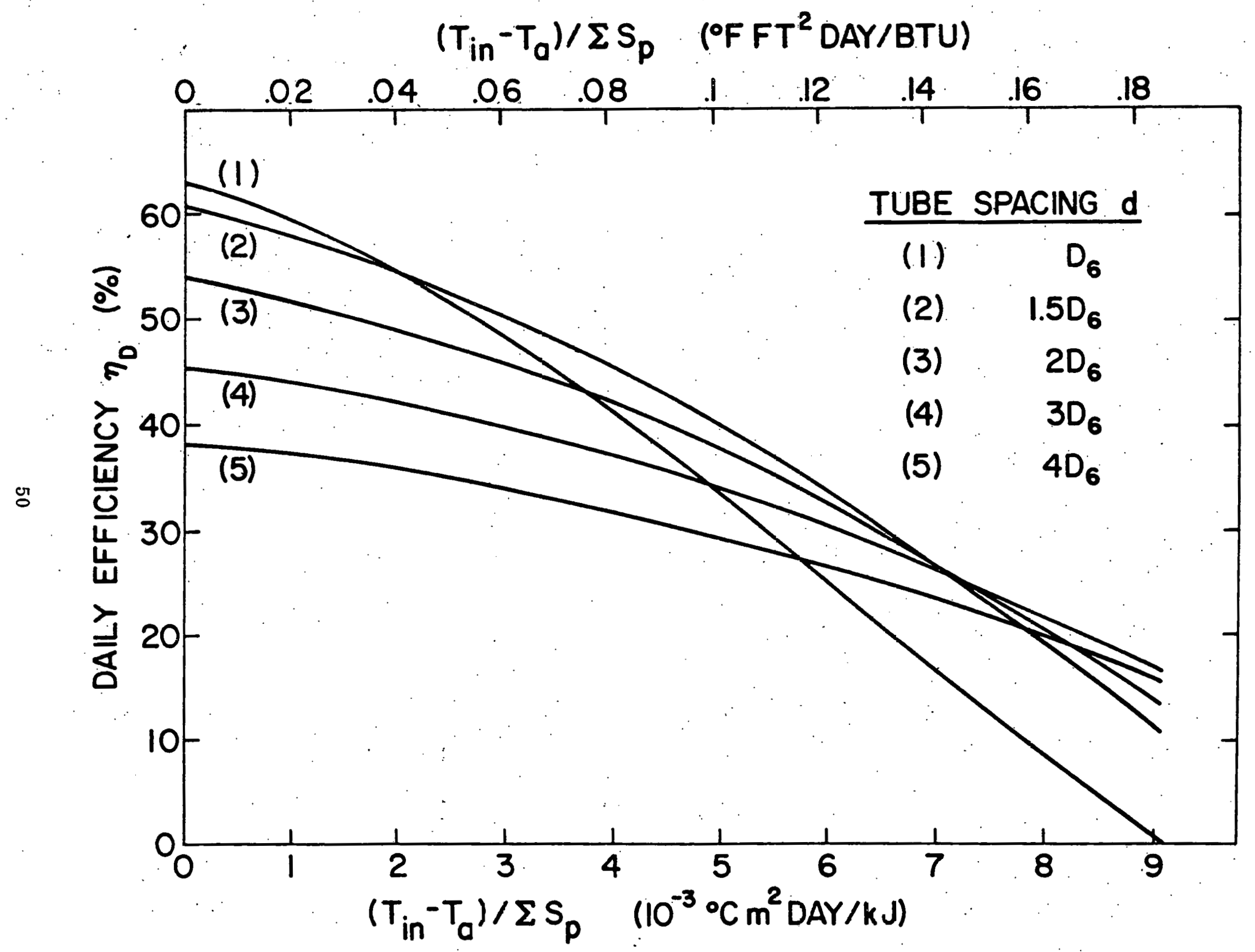

Figure 15 


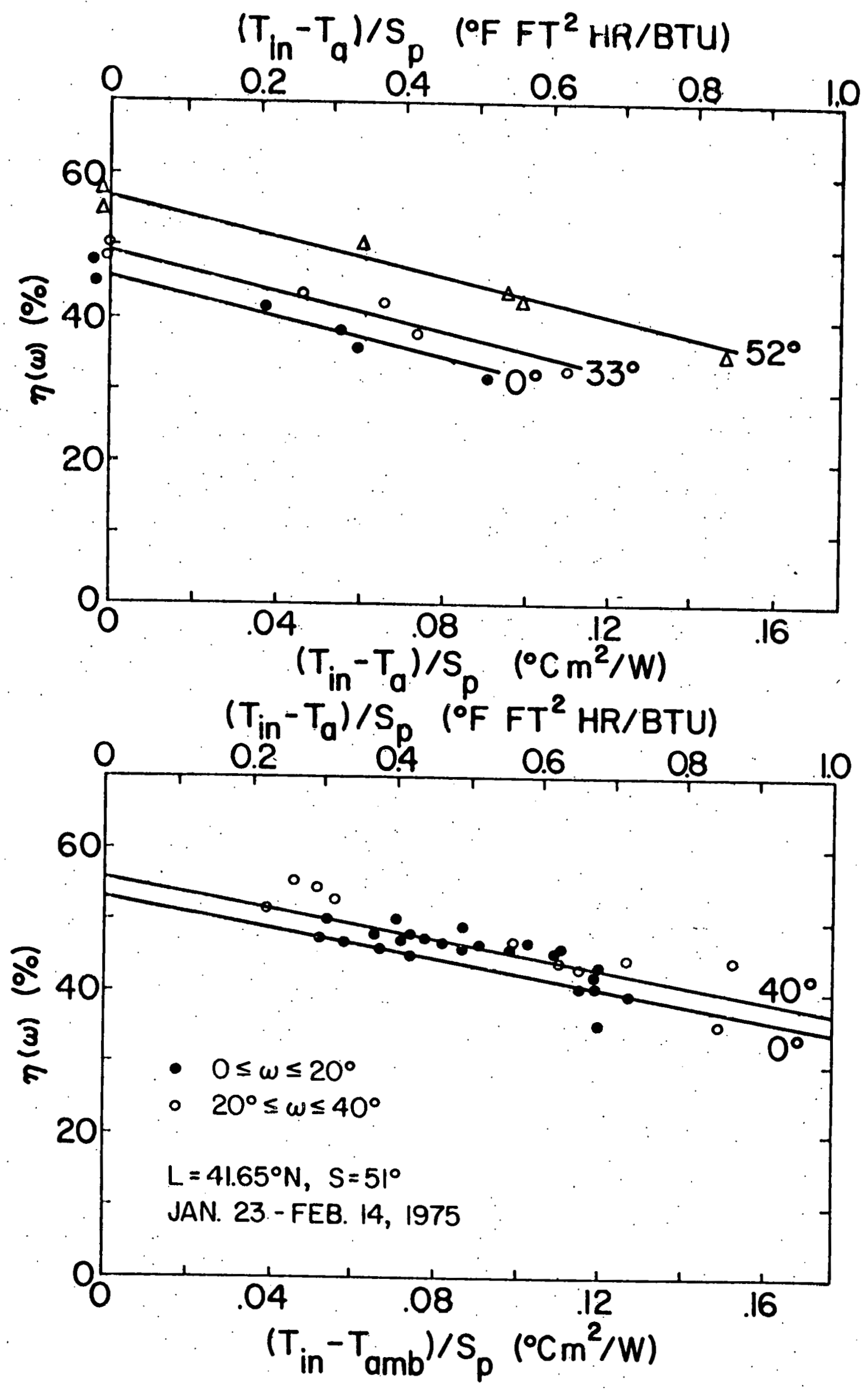


The following definitions of parameters and variables are used throughout the paper. We have attempted to use terms that are in current use in the body of literature on solar energy where possible. Subscripts are used in the paper to denote which component the parameter applies.

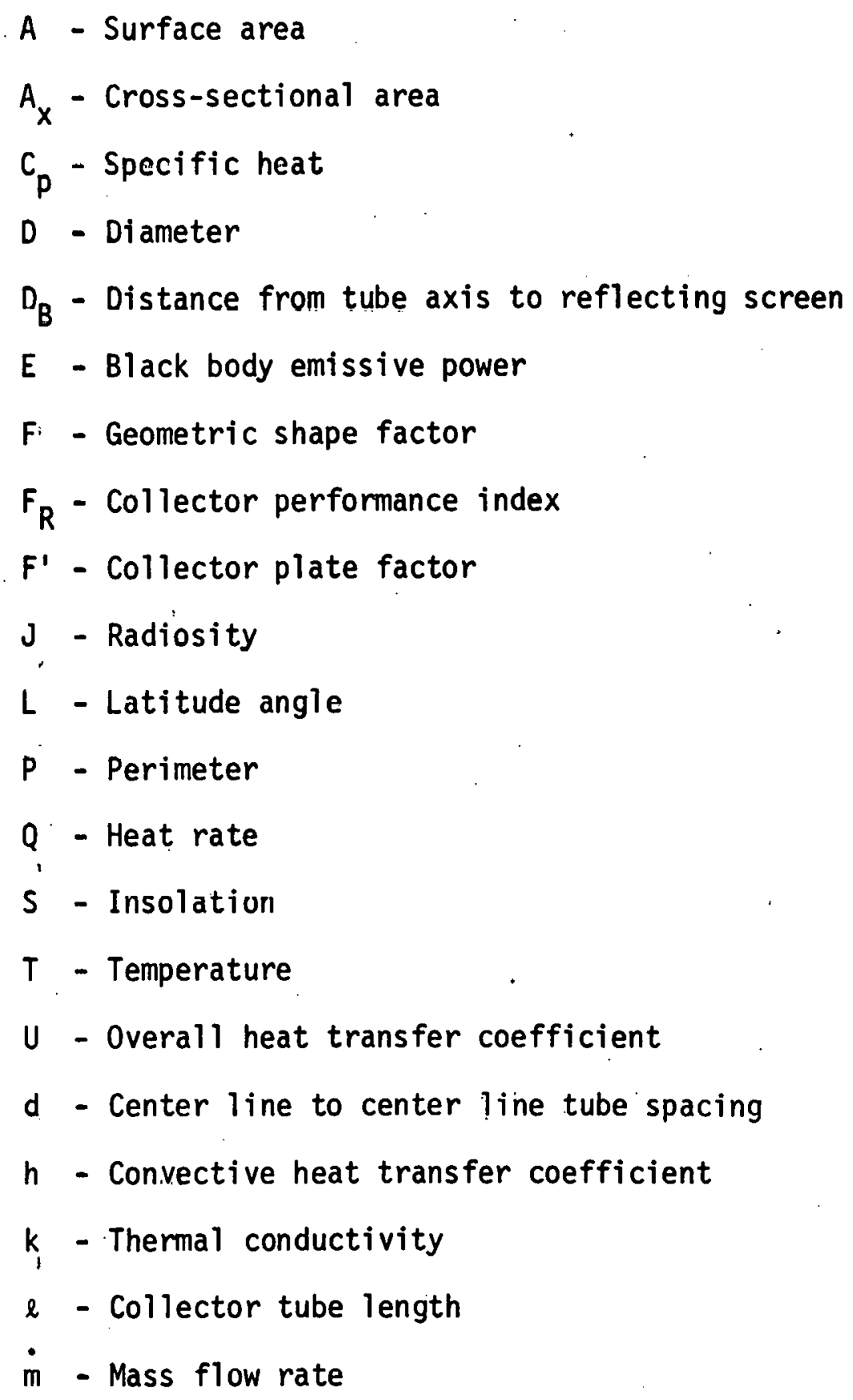


s - Collector tilt angle to horizontal

$t$ - Time coordinate

$\hat{\mathrm{t}}$ - Reduced time coordinate

$x$ - Space coordinate

$\xi$ - Reduced space coordinate

$\alpha$ - Collector absorptance

$\varepsilon$ - Emittance

$\delta$ - Declination angle

$\Delta$ - Back-reflected light parameter

p - Reflectance

$\rho_{f}$ - Heat transfer fluid density

$\omega$ - Hour angle

$\tau$ - Collector transmissivity

$\lambda_{1}$ - Thermal coupling parameter

$\lambda_{2}$ - Loss/flow parameter

$\sigma$ - Stefan-Boltzmann constant 